\title{
Tectonics
}

\author{
RESEARCH ARTICLE \\ 10.1029/2020TC006172 \\ Key Points: \\ - We use a thin sheet model of the \\ Norwegian Barents Sea lithosphere \\ to assess folding in response to \\ kinematics of the Greenland Plate in \\ the Paleogene \\ - Timing and extent of folding in the \\ Norwegian Barents Sea are \\ correlated with Greenland-Eurasia \\ plate interactions during the \\ Paleogene \\ - The oblique collision of Greenland \\ with Eurasia can explain many \\ Eocene contractional structures in \\ the Norwegian Barents Sea
}

Supporting Information:

- Supporting Information S1

Correspondence to:

S. Gac,

sebastien.gac@geo.uio.no

Citation:

Gac, S., Minakov, A., Shephard, G. E., Faleide, J. I., \& Planke, S. (2020).

Deformation analysis in the Barents Sea in relation to Paleogene transpression

along the Greenland-Eurasia plate

boundary. Tectonics, 39 ,

e2020TC006172. https://doi.org/

$10.1029 / 2020 \mathrm{TC} 006172$

Received 26 FEB 2020

Accepted 29 SEP 2020

Accepted article online 6 OCT 2020

(c)2020. American Geophysical Union. All Rights Reserved.

\section{Deformation Analysis in the Barents Sea in Relation to Paleogene Transpression Along the Greenland-Eurasia Plate Boundary}

\author{
Sébastien Gac $^{1}$ (D), Alexander Minakov ${ }^{1}$ (D), Grace E. Shephard ${ }^{1}$ (D), Jan Inge Faleide ${ }^{2,1,3}$ (D), \\ and Sverre Planke $\mathrm{I}^{1,3,4}$ iD \\ ${ }^{1}$ Centre for Earth Evolution and Dynamics (CEED), Department of Geosciences, University of Oslo, Oslo, Norway, \\ ${ }^{2}$ Department of Geosciences, University of Oslo, Oslo, Norway, ${ }^{3}$ Research Centre for Arctic Petroleum Exploration \\ (ARCEx), University of Tromsø, Tromsø, Norway, ${ }^{4}$ Volcanic Basin Petroleum Research AS, Oslo, Norway
}

Abstract Late Cretaceous-Cenozoic contractional structures are widespread in the Barents Sea. While the exact dating of the deformation is unclear, it can only be inferred that the contraction is younger than the early Cretaceous. One likely contractional mechanism is related to Greenland Plate kinematics at Paleogene times. We use a thin sheet finite element modeling approach to compute deformation within the Barents Sea in response to the Greenland-Eurasia relative motions during the Paleogene. The analytical solution for the 3-D folding of sediments above basement faults is used to assess possibilities for folding. Two existing Greenland Plate kinematic models, differing slightly in the timing, magnitude, and direction of motion, are tested. Results show that the Greenland Plate's general northward motion promotes growing anticlines in the entire Barents Sea shelf. Our numerical models suggest that the fan-shaped pattern of cylindrical anticlines in the Barents Sea can be associated with the Eurekan deformation concurrent to the initial rifting and early seafloor spreading in the northeast Atlantic. The main contraction phase in the SW Barents Sea coincides with the timing of continental breakup, whereas the peak of deformation predicted for the NW Barents Sea occurred at later times. Svalbard has experienced a prolonged period of compressional deformation. We conclude that Paleogene Greenland Plate kinematics are a likely candidate to explain contractional structures in the Barents Sea.

\section{Introduction}

The sedimentary infill of the Norwegian Barents Sea shelf is strewn with inverted structures (Figure 1). For example, seismic reflection data indicate that Mid-Miocene and older sediments are locally folded and form dome structures in sediment layers at the Vestbakken margin and in sedimentary basins, such as the Sørvestsnaget Basin, located in the western Barents Sea (Faleide et al., 1988; Gabrielsen et al., 1997; Kristensen et al., 2018). Older elongated contractional structures, many of which are located above basement faults, are observed in the Central Barents Sea. These structures are variously oriented, forming a fan-shaped pattern from north to south (Figure 1). Such SSW-NNE oriented structures are observed east of Svalbard (Norwegian Petroleum Directorate, 2017) and SE-NW oriented structures are recorded in the Southeast Norwegian Barents Sea (Gernigon et al., 2018; Hassaan et al., 2020). The exact timing and formation mechanisms of these inverted structures are unknown because much of the middle and late Cretaceous and Cenozoic sedimentary record has been erased during late Cenozoic regional uplift and erosion events (Dimakis et al., 1998; Henriksen et al., 2011; Nansen, 1904; Smelror et al., 2009). Thus, it can only be inferred that the contractional deformation is younger than the youngest preserved shortened layer of lower Cretaceous age.

Compressional stresses caused by lateral variations of gravitational potential energy (GPE) may explain some of the contractional structures in the Barents Sea region (Doré et al., 2008; Gac et al., 2016; Schiffer et al., 2018). The present-day GPE distribution models proposed by Schiffer et al. (2018) and Gac et al. (2016) imply that a wide area is under compression but nonelastic contraction is restricted to two compact regions: south of Bjørnøya (Schiffer et al., 2018), thereby explaining Miocene contraction observed in sediments at the Vestbaskken margin (Gac et al., 2016), and within a narrow strip in the SE Barents Sea (Gac et al., 2016). Hence, the deviatoric stresses related to the GPE alone, may not explain the observed fan-shaped contraction and basin inversion in the Central Barents Sea from north to south. 
(a) Structural map of the Barents Sea

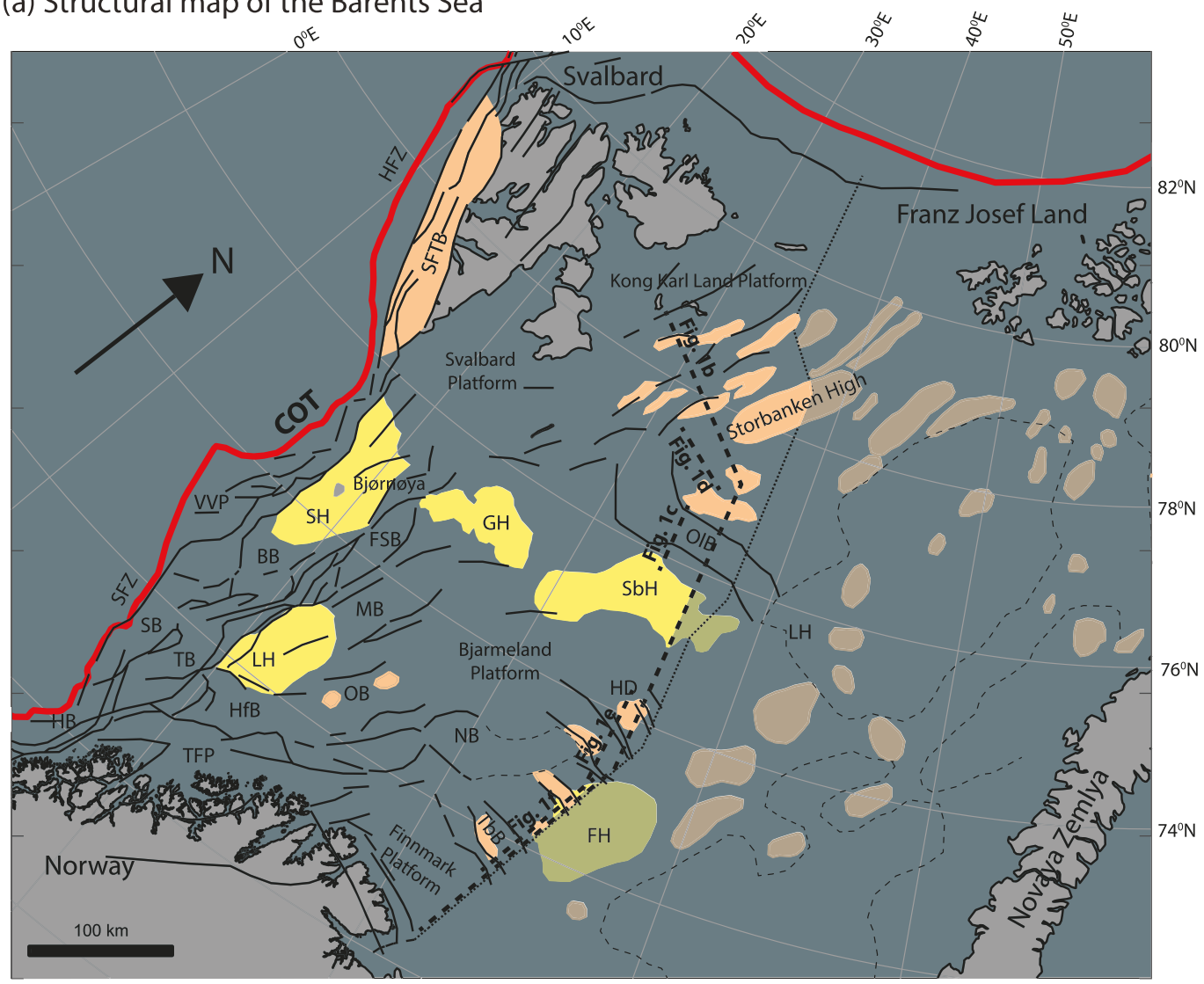

Structural highs

Anticlines \& domes

\section{(b) Seismic transect}

$\mathrm{N}$

Kong Karl Platform Storbanken High Olga Basin Sentralbanken High Haapet Dome Fedynsky High Tiddlybanken Basin Finnmark Platform

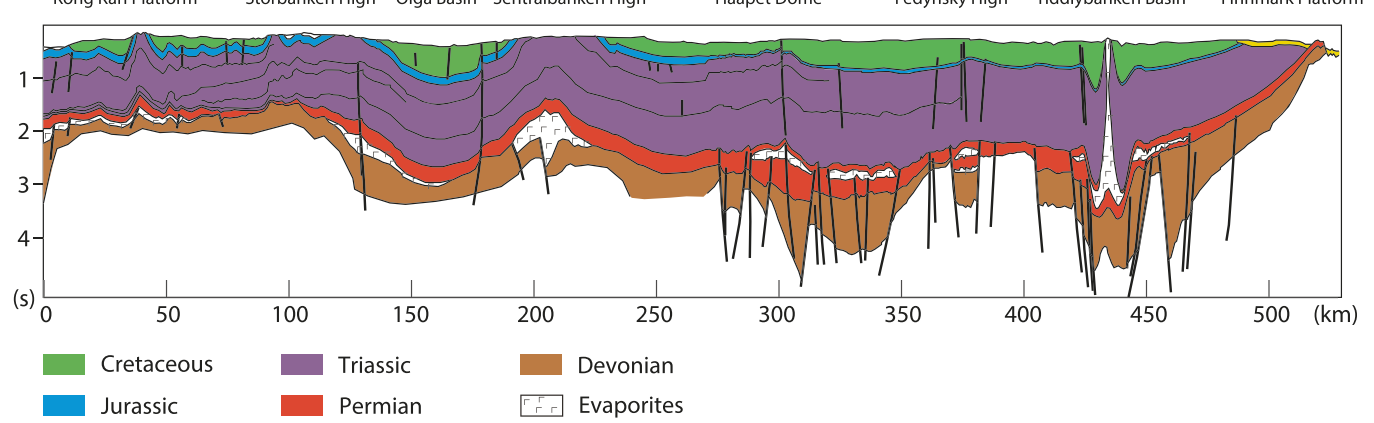

Figure 1. Inverted structures in the Barents Sea. The figure shows (a) a geological map of the Barents Sea with the main structural elements and inverted structures. Yellow and brown polygons are structural highs and anticlines, respectively (Gabrielsen et al., 1990; Hassaan et al., 2020; Norwegian Petroleum Directorate, 2017). The thin black lines represent faults (Faleide et al., 2015). The thin dashed lines represent basins and the dotted line is the border between Norway and Russia. The thick red line represents the continent ocean transition (COT) and the thick dashed black lines the location of the seismic transects. (b) An interpreted seismic transect crossing the eastern part of the Norwegian Barents Sea from north to south. The transect combines various seismic profiles from the Norwegian Petroleum Directorate (2017) and interpretations of Hassaan et al. (2020). Seismic transects crossing (c) the Olga Basin, (d) the Kong Karl platform, (e) the Haapet dome and the Fedynsky high, and (f) the Fedynsky high and the Tiddlybanken Basin. BB: Bjørnøya Basin, FH: Fedynsky High, FSB: Fingerdjupet Subbasin, GH: Gardarbanken High, HB: Harstad Basin, HD: Haapet Dome, HfB: Hammerfest Basin, HFZ: Hornsund Fault Zone, LH: Loppa High, MB: Maud Basin, NB: Nordkapp Basin, OB: Ottar Basin, OlB: Olga Basin, SB: Sørvestsnaget Basin, SbH: Sentralbanken High, SFZ: Senja Fracture Zone, SH: Stappen High, TB: Tromsø Basin, TbB: Tiddlybanken Basin, SFTB: Spitzbergen Fold and Thrust Belt, TFP: Troms Finnmark Platform, VVP: Vestbakken Volcanic Province. 
(c) The Olga Basin

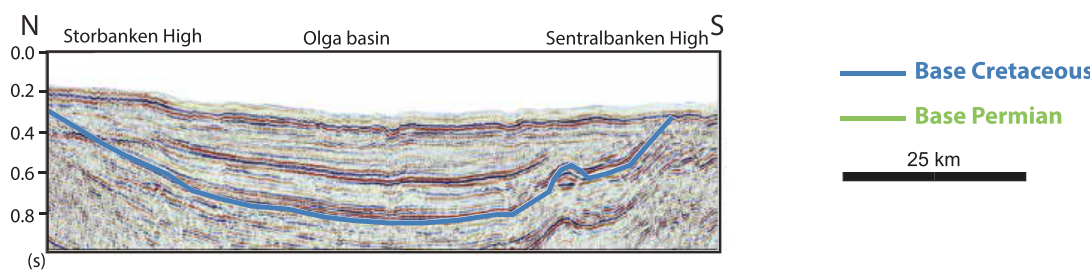

(d) The Kong Karl Platform

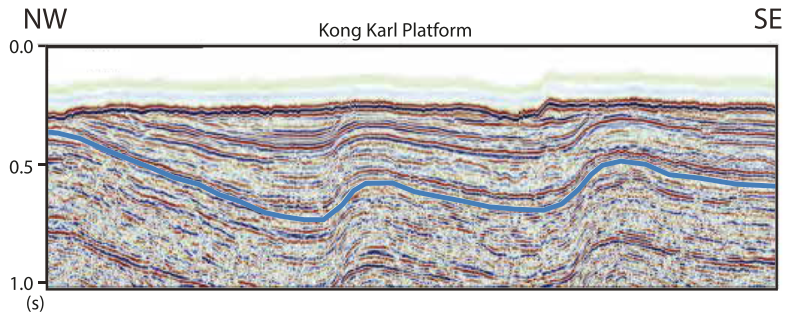

(e) The Haapet Dome

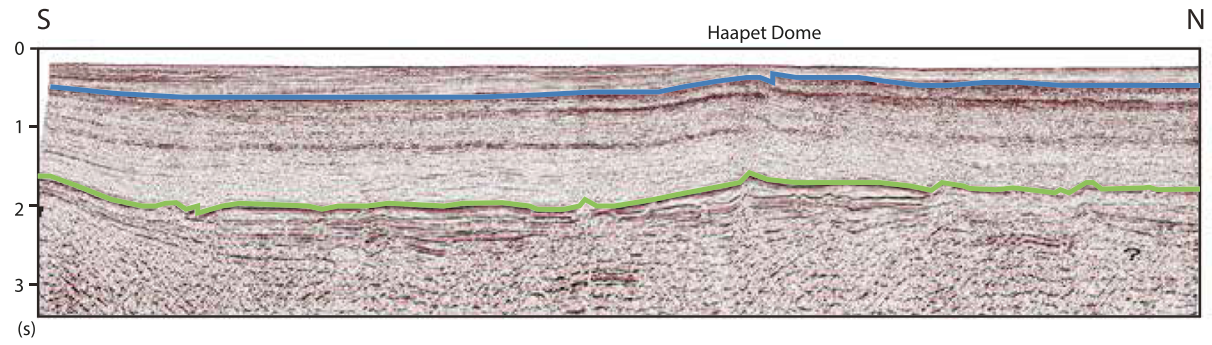

(f) The Tiddlybanken Basin and the Fedynsky High

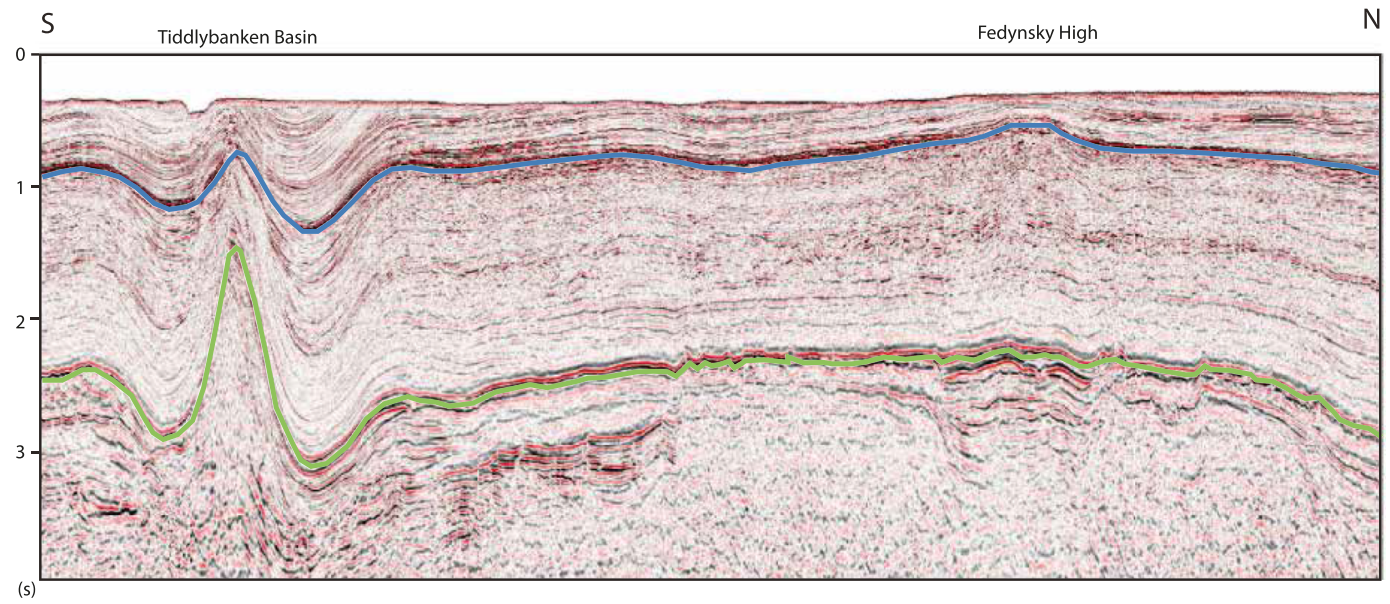

Figure 1. (continued)

Another possible contractional mechanism is related to the deformation along the evolving paleo-plate boundary between Greenland and Eurasia during the opening of the North Atlantic Ocean and associated changes in the Greenland Plate kinematics at Paleogene times (Figure 2). The Eurekan Orogeny (also termed Eurekan Deformation; e.g., Gion et al., 2016; Kerr, 1977; Piepjohn et al., 2016), contemporaneous to early seafloor spreading in the northeast Atlantic, involved deformation across Spitsbergen (the main island of the Svalbard archipelago), northern Greenland and the Canadian Arctic Islands. Piepjohn et al. (2016) 
(a) pre-Eurekan

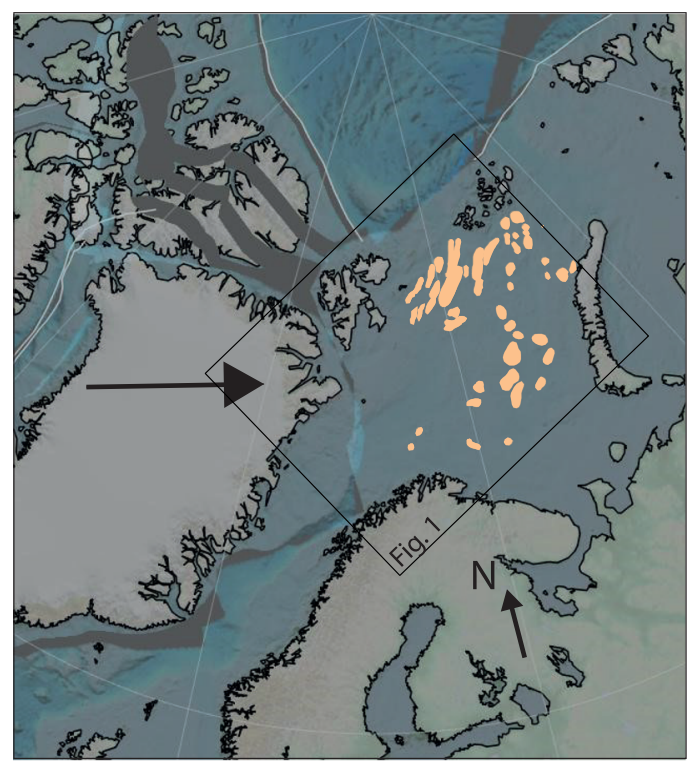

(c) Eurekan stage 2 - mid.-late Eocene

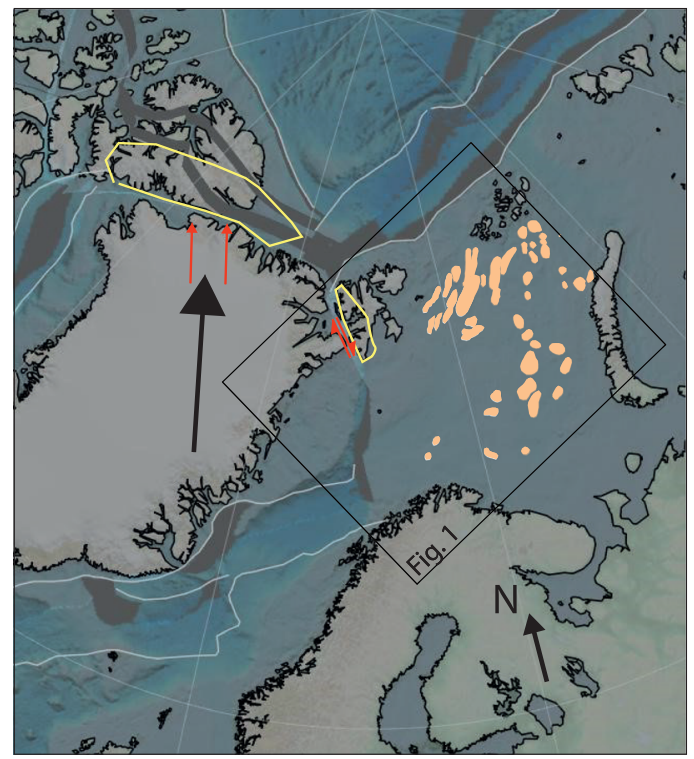

(b) Eurekan stage 1 - early Eocene

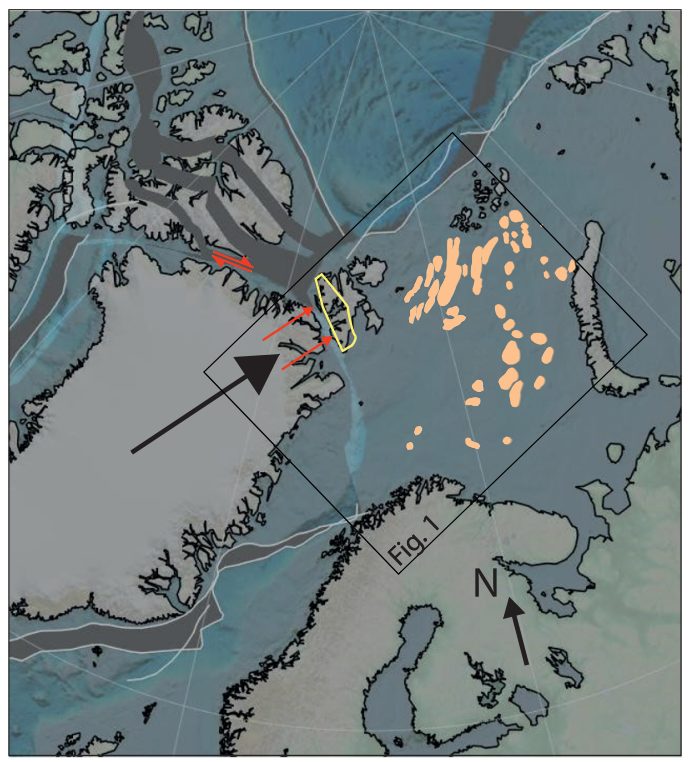

(d) post-Eurekan - Oligocene

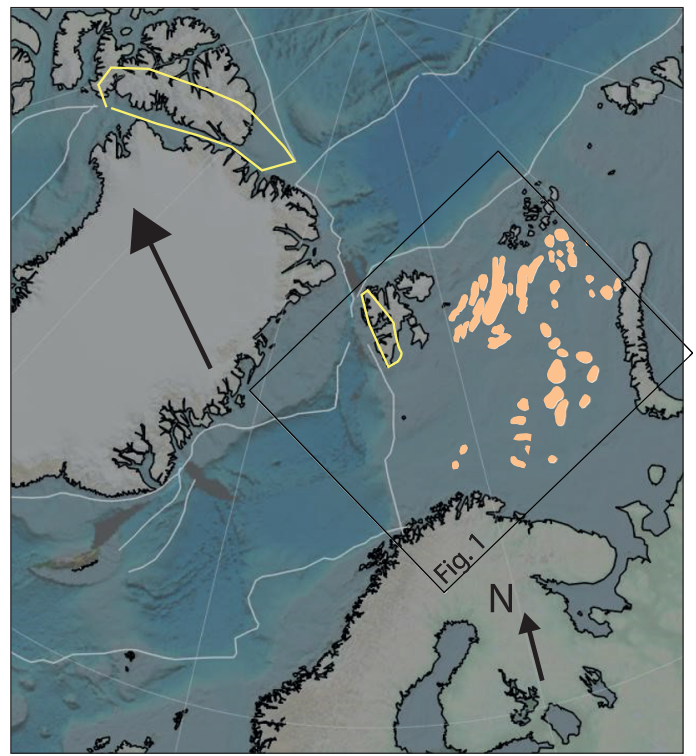

Figure 2. Paleogene reconstructions of the North Atlantic and Arctic domains, simplified and based on the two-phase Eurekan deformation model of Piepjohn et al. (2016). The figure shows paleogeographic reconstructions in a fixed Eurasia reference frame at (a) Pre-Eurekan stage, (b) Eurekan Stage 1, (c) Eurekan Stage 2, and (d) Post-Eurekan. The brown polygons represent the inverted structures that are compared to the models. The square represents Figure 1. Relevant tectonic deformation for each stage is shown as yellow polygons. The thick black arrow represents the direction of the overall Greenland plate direction. The red arrows represent the style of deformation (head-on collision and strike-slip). The thin black arrow in the lower right corner indicates the north.

identified two major tectonic phases of the Eurekan Orogeny; Stage 1 during the early Eocene (53-47 Ma), started immediately after breakup in the North Atlantic (marked by chron 24, 53 Ma) and ended when Greenland changed its drift direction (marked by chron 21, 47 Ma). The east to northeastward motion of Greenland relative to Eurasia caused a proposed head-on collision with the northern Barents Sea shelf initiating the West Spitsbergen fold-and-thrust belt and contemporaneous sinistral strike-slip motion along 
the Wegener Fault and Ellesmere Island north of Greenland (Figure 2b). This was followed by tectonic Stage 2 in the middle to late Eocene, related to final breakup within the North Atlantic (47-34 Ma Piepjohn et al., 2016). This new phase started when Greenland changed its drift direction (marked by chron 21, $\sim 47 \mathrm{Ma}$ ) leading to an overall northwestward motion of Greenland causing contraction within Ellesmere Island, and contemporaneous dextral transpression west of Svalbard (Figure 2c). This phase ended at chron 13 when sea floor spreading ceased in the Labrador Sea-Baffin Bay ( 34 Ma) and Greenland became part of North America (Figure 2d).

Stresses related to plate boundary forces can be conveyed in the lithosphere over hundreds of kilometers away from plate boundaries (Cloetingh \& Burov, 1996; England, 1987; England et al., 1985; Turcotte \& Schubert, 2002). It is thus possible that compression caused by the oblique collision between Greenland and Eurasia in the Paleogene may have diffused far into the Central Barents Sea shelf. This may cause folding and buckling of the crystalline crust and overlying sediments (Cloetingh \& Burov, 2011; Ziegler et al., 1995, 1998). Numerical and analog modeling shows that the continental lithosphere, when subjected to compression, can exhibit a complex deformation pattern including thickening, faulting, and buckling (Burov et al., 1993; Cloetingh et al., 1999; Davy \& Cobbold, 1991; Gac et al., 2013, 2014; Nielsen et al., 2005; Schmalholz et al., 2009; Sokoutis et al., 2005). In continental lithosphere, rheologically strong layers decoupled from each other by weaker ductile layers may cause the formation of folds with different wavelengths in sediments, crust, and mantle lithosphere. However, nondetached sediments will follow the lithospheric deformation (Burov, 2011; Cloetingh \& Burov, 2011; Stephenson \& Cloetingh, 1991).

Since the Paleozoic, the Norwegian Barents Sea shelf has experienced a long tectonic history of extensional and contractional deformation evidenced by a faulted and rugged basement (Faleide et al., 2008). Faults and other heterogeneities in the crystalline basement have a strong control on later sediment deformation and may nucleate contractional structures such as folds (Cooper et al., 1989). Hence, depending on the orientation and magnitude, the compression caused by the oblique collision between Greenland and Eurasia may have triggered folding of sedimentary strata (or reinforced folding of existing anticlines) in the Paleogene. These folds could be additionally amplified above reactivated pre-Cenozoic basement faults.

To test this hypothesis, we (1) evaluate the paleo-strain rates within the Barents Sea lithosphere (Eurasian Plate) related to the oblique collision between the Greenland Plate and Eurasia at latest Cretaceous-Eocene times, (2) assess the preferred strike of folds' axes in the predicted paleo-deformation field, and (3) quantitatively compare the strikes of modeled and observed contractional structures in the Central Barents Sea (the brown structures in Figure 1a).

We use a viscous thin-sheet approximation (England \& McKenzie, 1982) to compute the orientation of horizontal strain rates within the lithosphere in response to plate boundary forces. We solve the governing equations using a finite element method. We combine this numerical approach with the analytical solution for infinitesimal deformation of a single linear viscous layer, embedded in a uniform viscous medium and subjected to pure shear (Fletcher, 1991), to assess conditions for development of folding instability nucleated at small basement heterogeneities, aligned with a certain azimuth.

First, in order to understand the basic strain rates and predict the general fold geometry in the study region, we consider a simple model of a rounded rigid indenter representing the continental lithosphere of Greenland colliding with the Barents Sea and the Canada Arctic Archipelago regions. Second, we build more detailed mechanical and kinematic models to specify the mechanical response of the NW Eurasian lithosphere to the latest Cretaceous-Eocene (i.e., encompassing the entire Paleocene) Greenland motions. To achieve this, we use a more realistic geometry for the Greenland Plate (based on the Continent-Ocean Boundary published in Faleide et al., 2008) and a consistent kinematic model, as derived from two alternative published plate reconstruction models. Strain rates and folding are computed at different time intervals of the latest Cretaceous-Paleogene plate motion history.

Note that the timing of modeled intraplate deformation must be handled with care because the rates of Greenland's motion in the two published plate models somewhat differ from the two-phase kinematics of the Eurekean Orogeny described by Piepjohn et al. (2016), and also contradict some observables, especially the observed Eocene contraction at Svalbard. However, the aim of the paper is primarily to assess a numerical approach combining plate kinematic models and mechanical models of the lithospheric plates to predict 
intraplate contraction caused by the interactions of Greenland with Eurasia. Better constraining the kinematic model is beyond the scope of this paper.

\section{Observations}

The geometry of crystalline basement and overlying sedimentary strata in the Norwegian Barents Sea has a fan-shaped pattern of elongated positive (brown structures on Figure 1a) and negative (concave) structures. The composite seismic transect in Figure 1 crosses and/or passes by many of these structures. The transect crosses the eastern part of the Norwegian Barents Sea from north (Svalbard and Kong Karls Land Platform) to south (mainland Norway and Finnmark Platform) and combines several seismic profiles (Hassaan et al., 2020; Norwegian Petroleum Directorate, 2017). These structures are described in detail below.

The transect traverses late Paleozoic basins filled with Devonian and early to middle Carboniferous rocks which are in turn overlain by late Paleozoic to Mesozoic sequences (Figure 1b). These basins are separated by structural highs and platforms.

In the north, large parts of the Kong Karl Platform are marked by NNE trending anticlines (at $x=50 \mathrm{~km}$ in Figures $1 \mathrm{~b}$ and 1d) developed above normal faults (Grogan et al., 1999). These structures correlate with the NNE-SSW strike of Caledonian thrusts and nappes in the north (Barrère et al., 2009, 2011; Gernigon et al., 2014; Gernigon \& Brönner, 2012; Klitzke et al., 2019). The faults are mainly extensional and their ages are Paleozoic (Kairanov et al., 2018). The large anticlines were initiated in the late Jurassic (Norwegian Petroleum Directorate, 2017), and were reactivated during subsequent tectonic events, which are difficult to date since most of the middle to late Cretaceous and younger sedimentary strata were removed by late Cenozoic erosion (Norwegian Petroleum Directorate, 2017). Folding was amplified by evaporites deposited locally in Paleozoic half-grabens (Norwegian Petroleum Directorate, 2017).

Further south, the transect runs across several prominent crustal-scale fold structures (Figure 1b). The Storbanken High (at $x=100-120 \mathrm{~km}$ on Figure 1b), located south of Kong Karls Land Platform, is a deeply eroded elevated structure (Norwegian Petroleum Directorate, 2017). The youngest preserved strata cropping out at the seafloor are late Triassic. South of the Storbanken High, the Olga Basin (at $x=140-190 \mathrm{~km}$ in Figure 1c) is an E-W-oriented syncline and is a deep Paleozoic basin that subsided again later in the Cretaceous (Norwegian Petroleum Directorate, 2017). The basin's southern limit marks the northern boundary of the Sentralbanken High - a large deeply eroded elevated structure similar to the Storbanken High (Norwegian Petroleum Directorate, 2017) (at $x=190-230 \mathrm{~km}$ on Figure 1b). Along its southern flank, the structure gently dips toward the Bjarmeland Platform (at $x=230-350 \mathrm{~km}$ in Figure $1 \mathrm{~b}$ ), which has been tectonically stable since the late Paleozoic (Gabrielsen et al., 1990). The platform includes various salt-related domes such as the Samson and Norvarg domes in its western part (Gabrielsen et al., 1990) (Figure 1a).

Further south, the transect crosses the western edge of the Fedynsky High (at $x=350-400$ km in Figures $1 \mathrm{~b}$ and $1 \mathrm{f}$ ). The Fedynsky High is a large elevated structure surrounded by southern and northern depressions (Hassaan et al., 2020). The area is characterized by the presence of NW-SE trending smaller elongated dome structures, such as the Haapet Dome (at $x=310 \mathrm{~km}$ on Figure $1 \mathrm{~b}$ ) and, the composite west Fedynsky domes ( $x=380 \mathrm{~km}$ in Figures 1a, 1b, and 1f). These domes are located above NW-SE trending deep-seated Carboniferous grabens partially filled with late Carboniferous-early Permian evaporites (Gernigon et al., 2018; Hassaan et al., 2020). Seismic interpretation suggests the domes were initiated already in late Triassic (Dellmour et al., 2016) but were later reactivated in the late Jurassic-earliest Cretaceous (Hassaan et al., 2020). The main phase of reactivation took place later, possibly in the Eocene (Gernigon et al., 2018; Hassaan et al., 2020). Salt mobilization played a minor role in the formation of these domes, having rather been created by compression. South of the Fedynsky High the profile crosses the NW-SE oriented Tiddlybanken Basin, which initiated in Carboniferous times (at $x=430 \mathrm{~km}$ in Figures $1 \mathrm{~b}$ and $1 \mathrm{f}$ ). The NW-SE Carboniferous graben system and the Tiddlybanken Basin are cross-cut by the younger NE-SW oriented Nordkapp Basin (Hassaan et al., 2020). The graben system follows the NW-SE orientation of the Timanian terrane grain that extends from the Pechora system to the Norwegian SE Barents Sea (Gernigon et al., 2018; Roberts \& Siedlecka, 2002; Shulgin et al., 2018). Based on the analysis of magnetic and gravity anomaly trends, Klitzke et al. (2019) proposed the Timanian terrane extends further north, incorporating the Olga-Sørkapp Basin system. The transect ends at the border of the Finnmark Platform and is marked by shallowing of sediment layers approaching the Fennoscandian craton. 


\section{Method}

The geological and geophysical observations indicate that the elongated anticlines in the Barents Sea (Figure 1a) were formed above Paleozoic to early Mesozoic structures, such as basement escarpments, normal faults and salt bodies, and their main phase of formation most likely postdates the early Cretaceous.

We evaluate how likely it is that Paleogene transpression of Greenland against the western margin of Eurasia caused folding above inherited heterogeneities. This mechanism is tested by combining plate kinematic models of the North Atlantic, a thin sheet viscous model of lithosphere (England \& McKenzie, 1982), and an analytical solution for 3-D folding (Fletcher, 1991). This approach may provide a practical alternative to a more computationally expensive solution of the full 3-D problem of heterogeneous lithospheric deformation at a multiscale resolution.

The first step is to understand the basic fold patterns caused by an indenter colliding a continental lithosphere without the complications caused by structural and kinematic complexity. For this scenario, we model the mechanical response of the lithosphere when a simple rounded rigid indenter impacts continental lithosphere. The analytical solution for 3-D folding is then used to understand the spatial distribution of the folds.

In the next step, the indenter possesses a consistent Greenland Plate geometry and kinematic so to assess the intraplate deformation patterns induced by latest Cretaceous-Paleogene Greenland Plate motions. The latest Cretaceous-Paleogene Greenland Plate velocities have been quantified in two different published global kinematic models, namely Müller et al. (2016) and the earlier model of Seton et al. (2012) (which in turn are based on the regional North Atlantic data sets of Barnett-Moore et al., 2018; Gaina et al., 2009; Gaina et al., 2009; Roest \& Srivastava, 1989, respectively, as detailed below in the methods). As a first approach to predict the orientation of folds, the analytical solution for 3-D folding is used. In a second approach, the initial perturbations are imposed, and their orientations are set according to the strikes of observed basement faults in the Central Barents Sea. The analytical solution for 3-D folding then predicts the possibility and magnitude of folding above those initial perturbations along a transect crossing the central Barents Sea from north to south (Figure 1).

\subsection{Thin Sheet Viscous Model of Lithosphere}

The deformation of the lithosphere in response to applied plate boundary stresses and body forces is controlled by rheology. There are two types of models generally used to describe the lithosphere rheology for plate-scale modeling of deformation, the choice of which depends at which depth level the lithosphere conveys stresses (Thatcher, 2009). If a brittle/elastic upper crust is considered to be the strongest domain (weak mantle, or "crême brulée" model), stress is conveyed in the upper crust, and deformation is controlled by interactions between rigid blocks (discontinuous elastic models) (Pascal \& Gabrielsen, 2001; Thatcher, 2009). However, if the ductile mantle lithosphere is the strongest component ("jelly sandwich" model, Burov, 2011; Jackson, 2002) it can convey stress and its flow properties determine the surface deformation. In this latter case, a continuum approach is preferable. The latter approach is widely used to predict the orientation of depth-integrated lithospheric stresses (Bird, 1999; England \& McKenzie, 1982; Flesch et al., 2001; Ghosh et al., 2009, 2019; Medvedev, 2016). Both approaches have already been used to model regional lithospheric deformation and evaluate paleo-stress in intraplate settings caused by plate boundary forces. For example, using a rigid elastic lithosphere numerical modeling approach, Pascal and Gabrielsen (2001) estimated the stress distribution on the Norwegian margin created by the Mid-Atlantic ridge push force. Schiffer and Nielsen (2016) and Stephenson et al. (2020) used a thin sheet model of lithosphere with an elastic rheology to predict GPE-driven deviatoric stress in the North Atlantic and compared it with the World Stress Map data (Heidbach et al., 2010, 2018). On the contrary, Flesch et al. (2001, 2007) and Ghosh et al. $(2008,2009)$ modeled the continental lithosphere as a thin viscous sheet to estimate deviatoric stress resulting from various contributions such as GPE and mantle tractions.

We perform a forward mechanical modeling approach and compare the models with observation of deformation on a geological timescale (amplitudes and strikes of folds and inverted rift structures within sedimentary basins). We do not try to solve a formal inverse problem as for the present-day stresses (e.g., Flesch et al., 2001). In such studies, present-day stress observations, well-constrained plate-boundary geometry, relative plate velocities directly measured by GPS, and density structure of the whole lithosphere 
(a) Full model - shear BC

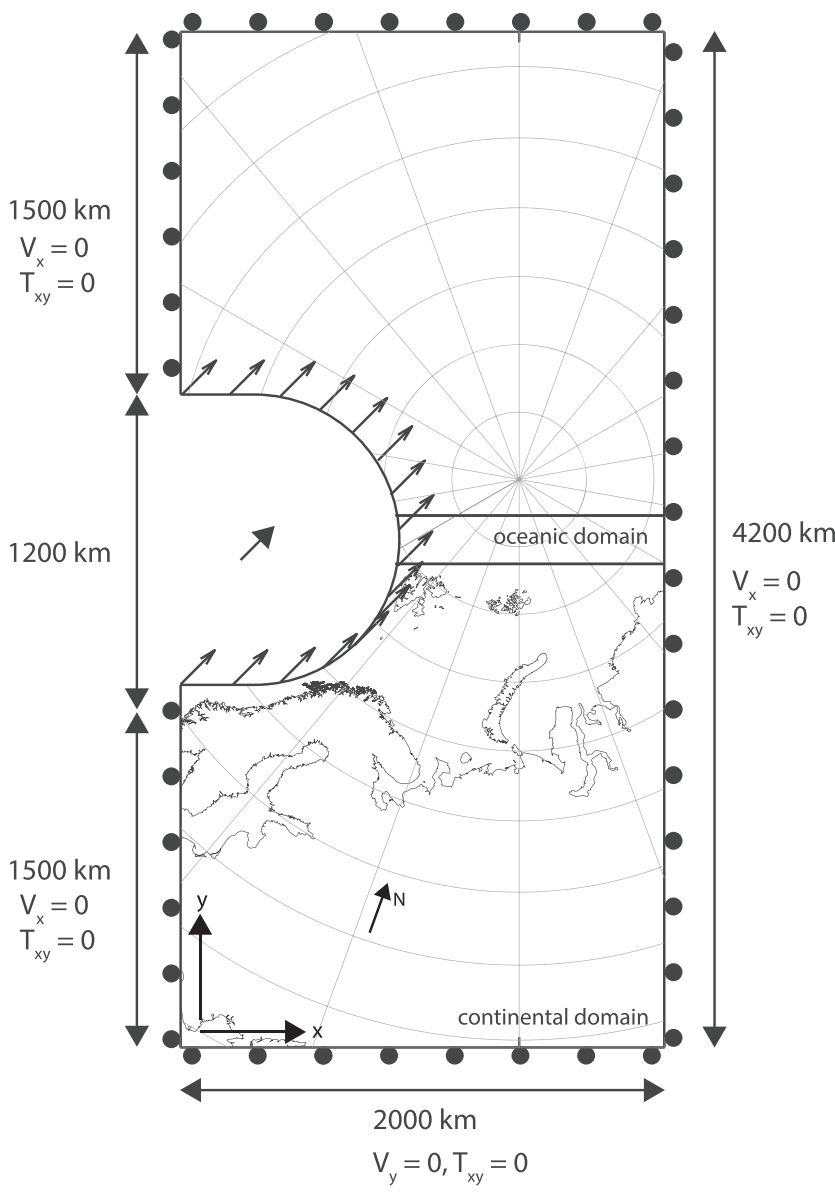

(b) Half model - no shear BC

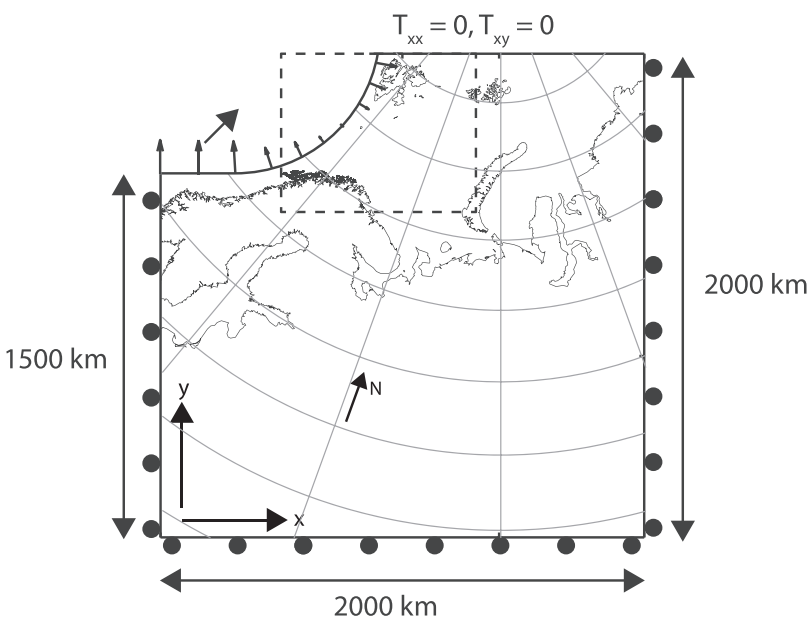

Figure 3. Model setup. The figure shows the geometry of the viscous model and the boundary conditions for (a) the full model with continuous (shear) boundary conditions applied at the indenter-Eurasia interface and (b) the half-model with "no shear" boundary conditions applied at the indenter-Eurasia interface. Velocities are imposed at the boundary between the indenter and Eurasia. Results are shown in the dashed box. constrained by gravity and seismological data may be utilized. Such detailed information is not available for a 30-60 Myr old continental Barents shelf. Therefore, we choose the approach of testing hypotheses and compare the predictions with geological observation at hand.

In our modeling approach we neglect the contribution of body forces to intraplate stresses and deformation in the Barents Sea shelf (unknown for Paleogene time) because we wanted to specifically address the contribution of collision between Greenland and Eurasia. Our "no gravity" choice is discussed later in section 5 .

We use a thin-sheet linear viscous approximation (England \& McKenzie, 1982) for a homogeneous lithosphere to solve for flow velocities driven by velocity boundary conditions and lateral variations in GPE. If the GPE gradients are zero the deformation is only due to boundary velocities. Strain rates are inferred from flow velocities. The flow of a thin incompressible viscous plate can be described by the following equations (Lechmann et al., 2011):

$$
\begin{aligned}
& 2 \partial_{x} \mu \partial_{x} v_{x}+\frac{1}{2} \partial_{y} \mu\left(\partial_{y} v_{x}+\partial_{x} v_{y}\right)+\partial_{x} \mu \partial_{y} v_{y}=\frac{1}{L} \frac{\partial \Pi}{\partial x} \\
& 2 \partial_{y} \mu \partial_{y} v_{y}+\frac{1}{2} \partial_{x} \mu\left(\partial_{y} v_{x}+\partial_{x} v_{y}\right)+\partial_{y} \mu \partial_{x} v_{x}=\frac{1}{L} \frac{\partial \Pi}{\partial y}
\end{aligned}
$$

Equation 1 is constrained by the velocity boundary conditions imposed at the limits of the computational domain:

$$
\begin{aligned}
& v_{x}=V_{x} \\
& v_{y}=V_{y}
\end{aligned}
$$

The boundary conditions $V_{x}$ and $V_{y}$ are detailed in section 3.3 and indicated in Figure 3. Strain rates are inferred from computed flow velocities:

$$
\begin{aligned}
& \dot{\varepsilon}_{x x}=\partial_{x} v_{x} \\
& \dot{\varepsilon}_{y y}=\partial_{y} v_{y} \\
& \dot{\varepsilon}_{x y}=\frac{1}{2}\left(\partial_{y} v_{x}+\partial_{x} v_{y}\right)
\end{aligned}
$$

where $\mu$ is viscosity, $\dot{\varepsilon}_{x x}, \dot{\varepsilon}_{y y}, \dot{\varepsilon}_{x y}$ are strain rates, and $v_{x}, v_{y}$ are the lithosphere mantle flow velocities, $\Pi$ is the gravitational potential energy (GPE) gradient (Molnar \& Lyon-Caen, 1988) and $L$ the reference depth $(200 \mathrm{~km})$. Deviatoric stresses are related to the computed strain rates as

$$
\begin{aligned}
\tau_{x x} & =2 \mu \dot{\varepsilon}_{x x} \\
\tau_{\mathrm{yy}} & =2 \mu \dot{\varepsilon}_{\mathrm{yy}} \\
\tau_{\mathrm{xy}} & =2 \mu \dot{\varepsilon}_{\mathrm{xy}}
\end{aligned}
$$

We solve these equations numerically using the standard Galerkin finite element method (Kwon \& Bang, 2000). The discrete form of Equation 1 can be written using the matrix notation:

$$
\mathbf{K} \mathbf{v}=\mathbf{F}
$$

where $\mathbf{K}$ is the global system matrix, $\mathbf{v}$ is the vector of velocities, $\mathbf{F}$ is the force vector. We solve this system of equations numerically for velocity unknowns given the velocity boundary conditions (according to the 
plate kinematic model) and forces due to lateral variation of GPE in the right-hand side of Equation 1. Following the standard method of Hughes (2000) and Kwon and Bang (2000), the boundary conditions are not included in the initial Equation 1. Instead they are set up in the matrix notation (Equation 4). The force vector $\mathbf{F}$ is modified with the known boundary conditions and the corresponding elements of matrix $\mathbf{K}$ are set to 1 (Kwon \& Bang, 2000).

We parameterize the computational domain using four-node quadrilateral elements with $10-\mathrm{km}$ distance between computation nodes. The source term in the right-hand side of Equation 1 related to lateral variation of GPE was ignored in most of our numerical simulations. We estimate the contribution of gravity force using computed present-day GPE in section 5.2.

\subsection{Analytical Solution for 3-D Folding}

To quantify the conditions for folding instability in our numerical simulations, we use the following assumptions: (1) Sediment layers fold when submitted to contraction; (2) local heterogeneities, such as salt bodies and/or faults, act as initial perturbations focusing contraction and initiating folding (Cooper et al., 1989); (3) sediment thickness is constant across the domain; (4) the sediment layer acts as a viscous layer; and (5) observed anticlines are generally elongated, as indicated by average aspect ratios length/width of $\sim 4-5$, when the aspect ratio is large enough it is reasonable to assume infinite folds. These assumptions allow us to use the analytical solution for 3-D folding of a viscous layer (Fletcher, 1991) to simulate growth of folds above initial perturbations.

Folding is an instability that may occur in multilayered viscous medium under compression. The amplitude of fold grows exponentially with time; $A=A_{0} \exp (\alpha t)$, where $\alpha$ is the relative fold growth rate depending on the fold geometry and the basic flow pattern, $A_{0}$ is the amplitude of initial perturbation. For a cylindrical fold compressed along $x$ axis and parallel to the $y$ axis, that is, perpendicular to the major principal direction, the relative growth rate given by Fletcher (1991) is

$$
\alpha=\left(\frac{q}{2}\right)\left(2 \dot{\varepsilon}_{H}+\dot{\varepsilon}_{h}\right)
$$

where $\dot{\varepsilon}_{H}$ and $\dot{\varepsilon}_{h}$ are the major and minor horizontal principal strain rates of the basic flow. They are derived from strain rates $\dot{\varepsilon}_{x x}, \dot{\varepsilon}_{y y}$, and $\dot{\varepsilon}_{x y}$ inferred from flow velocities (Equation 3) obtained by solving Equation 1.

The parameter $q / 2$ depends on the viscosity ratio between the embedded layer and the medium, and the wavelength of initial harmonic perturbation (Fletcher, 1991). We choose the fold wavelength that maximizes $q$ and, thus, represents the most rapidly growing mode. This particular fold wavelength is about 20 times the viscous layer thickness. The relative growth rate of a cylindrical fold oriented at an angle $\beta$ (positive counterclockwise) relative to the minor principal direction is obtained using standard transformation of strain rate tensor:

$$
\alpha=\left(\frac{q}{2}\right)\left[2\left(\dot{\varepsilon}_{H} \cos ^{2} \beta+\dot{\varepsilon}_{h} \sin ^{2} \beta\right)+\left(\dot{\varepsilon}_{H} \sin ^{2} \beta+\dot{\varepsilon}_{h} \cos ^{2} \beta\right)\right]
$$

\subsection{Model Geometry and Boundary Conditions}

\subsubsection{Simple Indenter Model}

As a first test, we use a simple model setup to understand the basic intraplate strain rate and fold patterns caused by a rounded rigid indenter pushing against a continental lithosphere containing an oceanic domain (Figure 3). The oceanic domain of the young Eurasia Basin is represented by a low-viscosity model region. The oceanic domain acts to decouple mechanically the lower and the upper half of the model (the decoupling conditions are discussed in the supporting information). All directions discussed herein are with respect to a fixed Eurasia reference frame. The model box is 2,000 km $\times 4,200 \mathrm{~km}$ large. A $600 \mathrm{~km}$ radius cylindrical indenter occupies the center-left part of the model and a $200 \mathrm{~km}$ wide oceanic domain occupies the central part of the model. The continental part of the model has a viscosity typical for continental lithosphere $\left(\mu_{\text {continent }}=5 \times 10^{22} \mathrm{~Pa} \mathrm{~s}\right.$ ), while the oceanic domain is given a 50 times smaller viscosity $\left(\mu_{\text {ocean }}=10^{21} \mathrm{~Pa} \mathrm{~s}\right)$ to approximate the weaker, younger, and warmer oceanic lithosphere near an oceanic spreading ridge. 
A velocity $(V)$ of $0.3 \times 10^{-9} \mathrm{~m} \mathrm{~s}^{-1}(\sim 1 \mathrm{~cm} / \mathrm{yr})$, is imposed for the indenter. This velocity value is chosen because the kinematic plate reconstruction models (Müller et al., 2016; Seton et al., 2012) suggest an average velocity of $\sim 1 \mathrm{~cm} / \mathrm{yr}$ for the Greenland plate in the early Cenozoic. The imposed velocity is parallel or oblique relative to the top boundary. The boundary conditions at the bottom and top boundaries of the model are free slip (Figure 3a). The right boundary is free slip, as is the left boundary except for along the perimeter of the indenter where the velocity is imposed. We test two types of boundary conditions at the interface between the indenter and Eurasia. At first, the interface is assumed to be continuous, that is both the tangential and the normal velocity components are imposed at the interface (Figure 3a). Second, only the velocity component normal to the interface is imposed and the tangential component is set to 0 . Under this boundary condition, the principal stress direction in the viscous model is roughly orthogonal to the contact surface of the rigid indenter (Figure $3 \mathrm{~b}$ ), so that the shear tractions imposed at the modeled plate boundary are minimized.

It is known from the geological record that the paleo-plate boundary north of Greenland was severely overprinted by late Cretaceous-Paleocene deformation caused by Greenland NE pushing in response to onset of sea floor spreading in the Labrador Sea and Baffin Bay at anomaly 31 (70 Ma) (Kristoffersen \& Talwani, 1977; Srivastava, 1978) or anomaly 27-26 (63-61 Ma) (Abdelmalak et al., 2019; Chalmers, 1991; Chalmers \& Pulvertaft, 2001) and, thus, is not well constrained. The early Cenozoic Eurekan deformation is extensively mapped onshore the Canada Arctic Archipelago (e.g., Piepjohn et al., 2016; Tessensohn \& Piepjohn, 2000). The Eurekan orogenic zone represents an amalgamation of several tectonic terranes. The structural evolution, interactions between the blocks and associated amounts of deformation can be sometimes very difficult to infer based on structural observations alone. In order to integrate the observations in a regional quantitative framework, Gion et al. (2016) developed plate reconstruction for the Eurekan orogeny using a deformable plate approach (as opposed to rigid plates) using GPlates. Yet kinematic modeling requires predefined regions of deformation, and thus it can be difficult to reconcile structural observations and model predictions. In our model setup, the results for the region north of Greenland is only provided for a simplified rounded indenter geometry (See figures in the supporting information), so that the problem of modeling of multiple mechanical blocks within the Eurekan orogeny was partly avoided. Our main focus here is on the Barents Sea region, and, therefore, we have chosen presenting results only for the lower half of the model (Figure 3b), assuming that the young ocean domain of the incipient Eurasia Basin efficiently decouples the two parts of the model. This "half" model box is $2,000 \mathrm{~km} \times 2,000 \mathrm{~km}$, and the $600 \mathrm{~km}$ radius cylindrical indenter occupies the top-left part of the model (Figure $3 \mathrm{~b}$ ). The top boundary is set free in order to simulate a rifting zone. In the supporting information, we show the effect of the upper half of the model on the deformation in the Barents Sea (Figure S1). Computed deformation for this "full" Barents Sea shelf domain are very similar to those computed for the half model (see Figure S2 in the supporting information).

In summary, three simple indenter models are tested in the result section (section 4). In the first one, the velocity imposed on the indenter is parallel relative to the top boundary and the interface is continuous. In the second one, the imposed velocity is oblique and the interface is continuous. In the last model, only the component normal to the Greenland-Eurasia boundary is imposed and the component that is tangential to the Greenland-Eurasia boundary is set to 0. This approximates no shear tractions at the Greenland-Eurasia boundary.

\subsubsection{Plate Kinematic Model Setup}

Next, models with a more realistic regional setup than those of the simple indenter model above are run. Geometries and velocities consistent with published plate kinematics are used in order to evaluate the successive intraplate strain rate fields and fold patterns caused by Greenland-Eurasia relative motions in latest Cretaceous-Paleogene times.

The velocity of the Greenland Plate is derived from two sets of published plate motion models of Greenland-Eurasia relative motion from latest Cretaceous (78 Ma) to middle Eocene times (45 Ma): model M1 (global model of Müller et al., 2016), which is based on regional rotations as published in Gaina et al. (2009) and Barnett-Moore et al. (2018); and model M2 (global model of Seton et al., 2012), which was built for these times on the regional models of Gaina et al. (2009) and Roest and Srivastava (1989). The finite rotations used are provided in the supporting information (Text S5). These two alternative models (M1 and M2) are selected because they have slightly different relative motions predicted between Greenland 
(a)

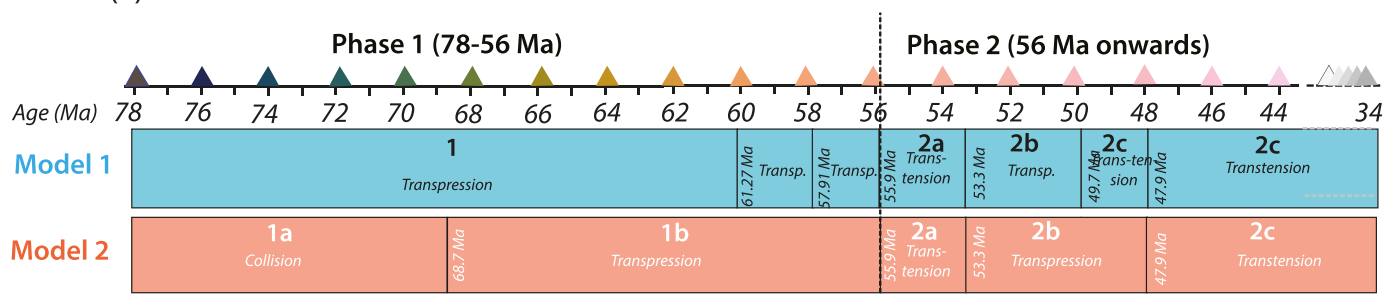

(b)

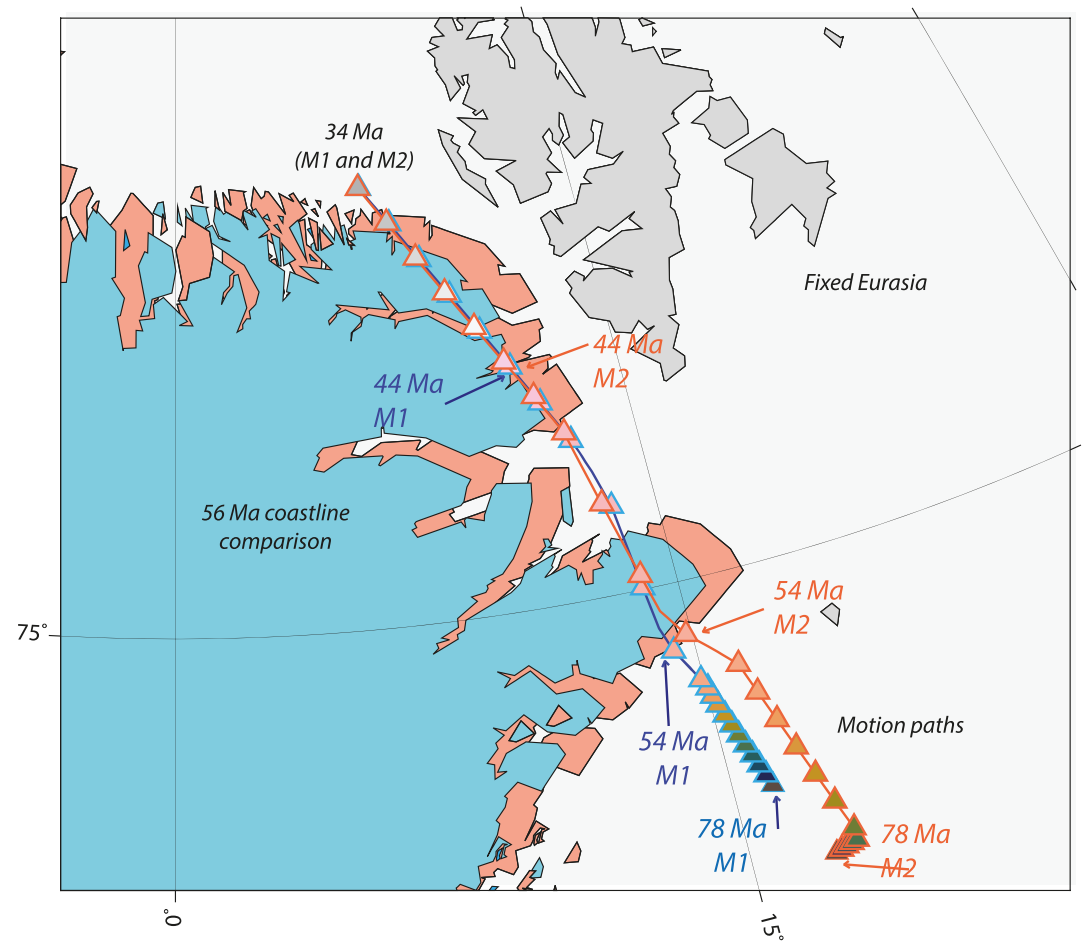

Figure 4. Summary of the two alternative plate reconstructions; M1 (blue) based on Barnett-Moore et al. (2018) and Gaina et al. (2009), and M2 (red) based on Gaina et al. (2009) and Roest and Srivastava (1989). Times shown are for the model run between 78 and $33 \mathrm{Ma}$. Corresponding finite rotations are provided in the supporting information files. (a) Summary of the phases for each of the models. The lines are drawn according to the finite rotation timings but summarized in text to the rounded million year increment inclusive for the two phases and subphases.

Transpressional, transtensional, or oblique collision regimes are indicated in italics. (b) Reconstructed coastline of Greenland with respect to a fixed Barents Sea shelf (Eurasia plate) at 56 Ma, when M1 (blue) and M2 (red) have maximum offset in relative location. Overlain are tectonic motion paths for M1 and M2 (initial point based on a location at $33 \mathrm{Ma}$ when the modeled reconstructions for both M1 and M2 are identical); the triangles indicate the location of that rotated point (derived at $33 \mathrm{Ma}$ ) in $2 \mathrm{Myr}$ increments back to $78 \mathrm{Ma}$ for the two models. Color coding for the times as shown in panel (a).

and Eurasia in the Paleocene (Figure 4). The two kinematic models encompass some of the uncertainties in reconstructions of latest Cretaceous-Paleogene North Atlantic plate kinematics; however, they are also problematic because of impermissible predicted continental overlaps between Greenland and the Barents Sea shelf and Norwegian margin during these times (and earlier) (Figure 4), and still require reconciliation with structural and geochronological observations of the Eurekan deformation event. The overlapping areas may also indicate late Cenozoic crustal extension linked to the transtensional regime at the plate boundary. The overlap issue, however, is not a limiting factor in our model setup due to the plate boundary being manually implemented to be located between the restored Greenland and Spitsbergen coastlines, and the use of plate velocities as applied at the boundary. Despite these issues, both M1 and M2 are suitable for testing more realistic boundary conditions and the first-order response to kinematic forcing. For both models, we use the GPlates software (Boyden et al., 2011) to compute the 
successive positions, velocities, and orientations of the Greenland Plate with respect to a fixed Eurasian Plate at $1 \mathrm{Myr}$ intervals from latest Cretaceous (78 Ma) to Eocene (45 Ma) as dictated by the published finite rotations (see Text S5 in the supporting information).

The viscous model is divided into three homogeneous regions: there are two continental domains (Eurasia and Greenland) and one oceanic domain (the North Atlantic oceanic domain). The plate boundary between Greenland and Eurasia is based on the restored location of the COB along the western margin of the Barents Sea from the study of Faleide et al. (2008). The plate boundary is updated with 1 Myr time intervals. The cumulative finite deformation is not computed.

The bottom (southern) and right (east) boundaries of the model are free slip. Since the early Cenozoic the northern Barents Sea is bordered by a rift (then mid-ocean ridge) probably reaching Greenland (Døssing et al., 2013). It is assumed that such a rift area acts as a weakness zone and therefore does not convey stresses. The top boundary of the model is, therefore, set free.

Numerical box dimensions are made large enough to avoid edge effects in the area of interest (the Barents Sea shelf) (see Figure S2 in the supporting information). The extracted velocities for the Greenland Plate for the two alternative models (as loaded into GPlates) are computed on a sphere and then were converted into a "flat Earth" coordinate system where deformation computations are performed. A polar stereographic projection is used as it minimizes distortions related to projections in polar regions.

Similar to the rounded rigid indenter model considered before, we tested the two types of boundary conditions at the Greenland-Eurasia plate boundary. First, the velocities are assumed to be continuous across the Greenland-Eurasia plate boundary, that is, both the normal and tangential component of the indenter velocity are imposed. The two models M1 and M2 with this type of boundary conditions are shown in the supporting information (Figure S3). Second, "no shear" boundary conditions are imposed at the interface, that is, only the component normal to the Greenland-Eurasia boundary is imposed and the component that is tangential to the Greenland-Eurasia boundary is set to 0 . The two models M1 and M2 with this type of boundary conditions are shown below in section 4 .

\section{Results}

\subsection{Indenter Model}

This simple model evaluates the mechanical effects of a rounded rigid indenter impacting a viscous plate representing continental lithosphere. Three indenter models are tested. In the first two models, both normal and tangential components of the indenter velocity are applied at the boundary between the indenter and the continent (Figures 5a-5d). In the third model, only the component of indenter velocity that is normal to the indenter-continent interface is applied (Figures 5e and 5f).

In the first model, the indenter is pushing rightward (eastward), in a direction parallel to the top boundary (Figure 5a). The indenter push causes large $x$-oriented (WSW-ENE to W-E) shortening rate (the major principal rate of deformation $\varepsilon_{H}$, whose magnitude is indicated by the length of the blue lines), and $y$-oriented extension (NNW-SSE to N-S) rate of deformation (the minor principal strain rate $\varepsilon_{h}$, red lines) in the Barents Sea shelf. Southward, principal strain rates gently rotate clockwise and shortening rate decreases.

At each point of the model, the modeling predicts that the initial perturbations that give the maximum fold growth rate are perpendicular to the direction of the maximum compressive rate of deformation $\varepsilon_{H}$ (Figure 5b). We refer to those trends as "favored strikes" of the fold axis. In front of the indenter, favored strikes are roughly perpendicular to the direction of the indenter motion. Southward, they gently rotate clockwise and become oblique to the indenter-continent interface. The magnitude of the relative fold growth rate $\alpha$ is given by Equation 7 and is indicated by the length of the strikes. The regional decrease in contraction rate away from the indenter causes the amplitude of fold growth rate to decline, from a maximum $\sim 10^{-14} \mathrm{~s}^{-1}$ near the indenter down to $\sim 10^{-16} \mathrm{~s}^{-1}$ in the south.

In the second model, the indenter is pushing obliquely to the top boundary with an angle of $45^{\circ}$ (Figure $5 \mathrm{c}$ ). The indenter push causes large SW-NE to W-E oriented shortening rate $\varepsilon_{H}^{\cdot}$ and NW-SE to N-S oriented extensional rate $\varepsilon_{h}$ in the Barents Sea shelf. Southward, the principal strain rates hardly rotate, and contraction rapidly decreases in amplitude. In the Barents Sea shelf, favored orientations of folds are oriented 


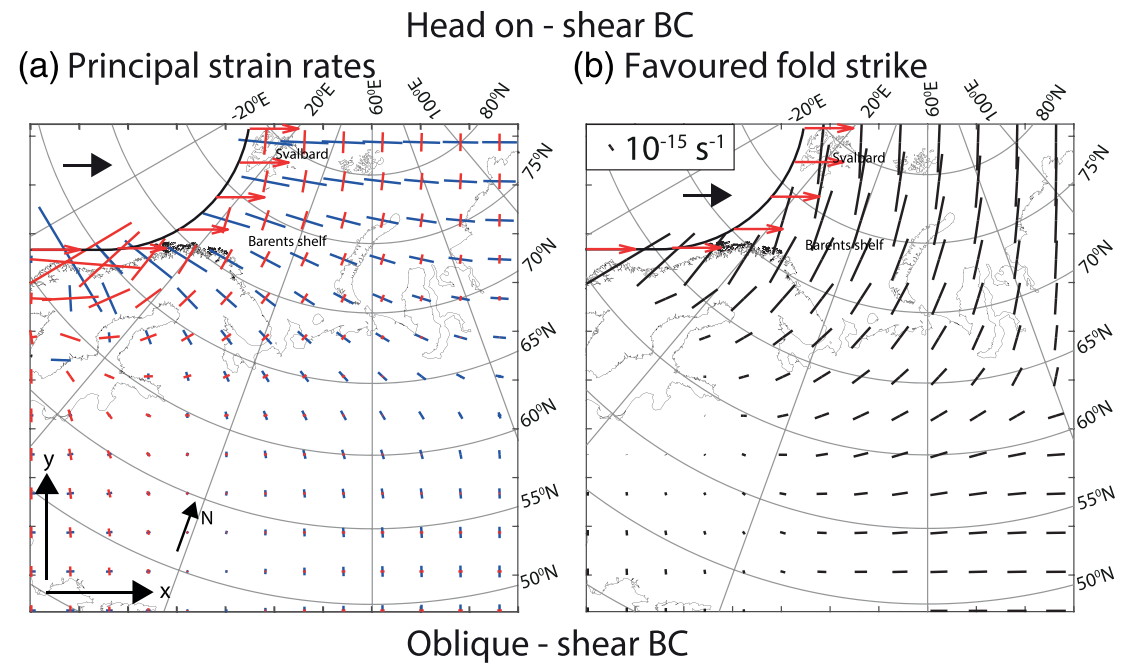

(c) Principal strain rates

(d) Favoured fold strike
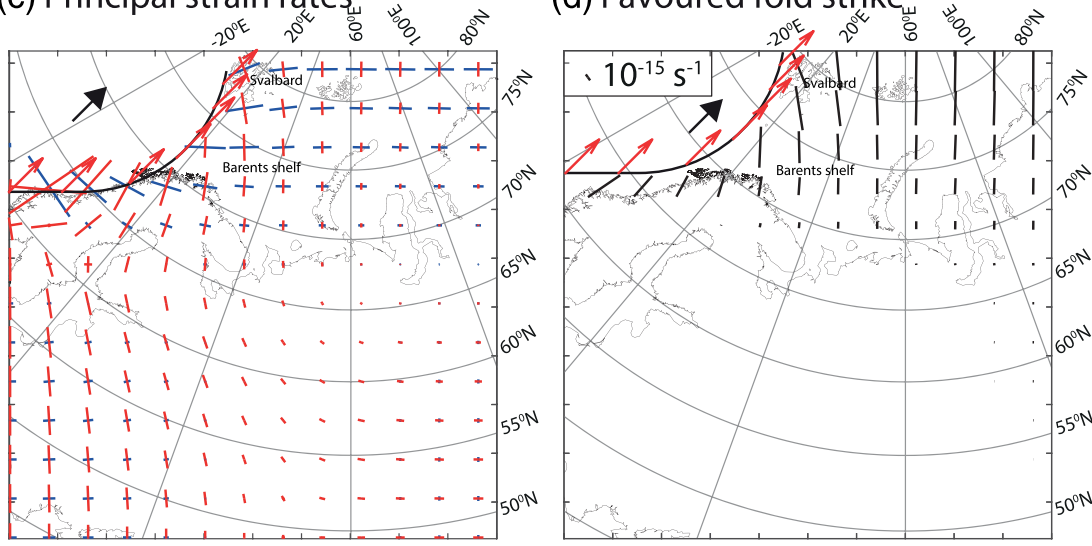

Oblique - no shear BC

\section{(e) Principal strain rates}

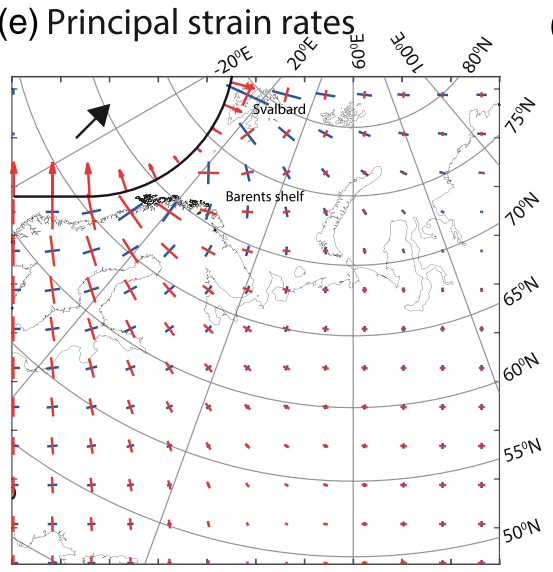

(f) Favoured fold strike

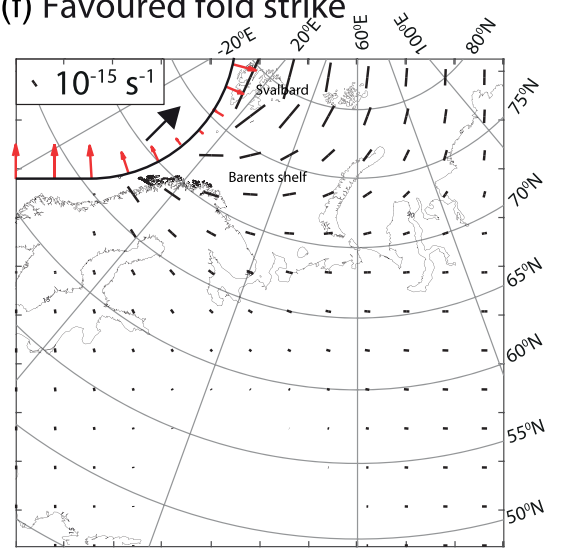

Figure 5. Modeled strain rate and preferential fold strike for the indenter models. The figure shows (a) principal strain rate for indenter pushing rightward and continuous (shear) boundary conditions applied at the indenter-Eurasia boundary, (b) the preferential direction of folding for indenter pushing rightward and continuous (shear) boundary conditions applied at the indenter-Eurasia boundary, (c) principal strain rate for oblique pushing of the indenter and continuous (shear) boundary conditions applied at the indenter-Eurasia boundary, (d) the preferential direction of folding for oblique pushing of the indenter and continuous (shear) boundary conditions applied at the indenter-Eurasia boundary, (e) principal strain rate for indenter pushing obliquely and no shear boundary conditions applied at the indenter-Eurasia boundary, (f) the preferential direction of folding for indenter pushing obliquely and no shear boundary conditions applied at the indenter-Eurasia boundary. Shortening rates are shown in blue and extensional rates are shown in red. Favored folds are represented with black streaks. The length of the streak is proportional to the amplitude of growth rate $\alpha$. 
NW-SE to N-S (Figure 5d). A NNW-SSE folding trend is predicted east of Svalbard. In the north, large contraction gives large fold growth rates. The rapid southward decrease in contraction rate $\varepsilon_{H}$ causes fold growth rate to regionally decrease until it vanishes.

The third model is a variation on the second model (the indenter is still pushing obliquely to the top boundary with an angle of $45^{\circ}$ ), but only the component of indenter velocity normal to the indenter-continent boundary is applied and the tangential component is null (Figure 5e). The normal velocity is controlled by the local angle between the boundary tangent and the velocity vector. The applied normal velocity is maximum near the top boundary. It then progressively decreases southwestward along the boundary as the angle between the boundary tangent and the velocity vector approaches $0^{\circ}$. Thereafter, the indenter velocity becomes oriented inward the indenter, that is, the angle between the boundary tangent and the velocity vector becomes negative; extension is applied.

The indenter push causes large $x$ oriented shortening rate $\varepsilon_{H}$ in the direction normal to the interface, near the top boundary (Figure 5e). Southwestward, along the indenter continent boundary, principal strain rates firmly rotate clockwise as they closely follow the curvature of the indenter. As far as the applied normal velocity is positive, the contractional principal strain rates remain subnormal to the interface though contraction decreases in amplitude to the benefit of extension. This gives favored folds that are roughly tangential to the indenter boundary (Figure 5f). This is the case in most of the Barents Sea shelf. In contrast, where applied velocity becomes negative (i.e., extension), the contractional principal strain rates tend to become parallel to the interface hence favored folds tend to be normal to the indenter boundary. However, further southwestward extension rapidly dominates preventing any folding. The amplitude of maximum fold growth rate declines strongly away from the indenter, from a maximum $\sim 5 \times 10^{-15} \mathrm{~s}^{-1}$ near the indenter until it vanishes in the south.

\subsection{Models Consistent With Plate Kinematic Reconstructions}

For the two kinematic models (M1 and M2), the strain rate response is computed for each Myr from latest Cretaceous ( $78 \mathrm{Ma}$ ) to middle Eocene times (45 Ma). We then look at the effects of the evolving strain rate field on the orientation and amplitude of folds at different times. In the models that we show, "no shear" boundary conditions are applied at the Greenland-Eurasia boundary. Results are computed in the entire numerical domain but they are shown in a domain restricted to the Barents Sea shelf (Figure 6). We have also tested models whereby both normal and tangential velocity components of the Greenland Plate are applied at the Greenland-Eurasia boundary. Those models are shown in the supporting information (Figure S3).

\subsubsection{Model M1}

For plate motion model M1, the latest Cretaceous-Paleogene motions of the Greenland Plate relative to a fixed Eurasia Plate can be summarized via several phases of motion as based on the finite rotations (Figure 4), implemented into the numerical modeling with a 1-Myr time increment. It is worth noting that it is somewhat difficult to assign strictly transpressional or transtensional regime along the continental margin because of the north to south variability in the geometry of the plate boundary. At 78-56 Ma Greenland moves very slowly ( $0.3 \mathrm{~cm} / \mathrm{yr})$ northwestward relative to Eurasia (Phase 1; strike-slip/transpression). The continental breakup occurs in the North Atlantic at $56 \mathrm{Ma}$, and the Greenland Plate subsequently moves overall north-northwestward at the increased rate of $\sim 1.3 \mathrm{~cm} / \mathrm{yr}$ (Phase 2 ; subphase a of transtension). This is followed by a short strike-slip/transpressional phase at $52 \mathrm{Ma}$ (Phase 2 subphase b) and increased velocity $(\sim 2.5 \mathrm{~cm} / \mathrm{yr})$. After $49 \mathrm{Ma}$, the Greenland Plate slows down and there is a smooth transition to a transtensional regime (Phase 2 subphase c). The Greenland Plate continues to drift away from the Barents Sea margin at $\sim 1 \mathrm{~cm} / \mathrm{yr}$.

The kinematics of the Greenland Plate causes deformation in the adjacent Barents Sea shelf. The crust and sediments generally deform plastically through faulting if a certain yield stress is exceeded. We apply a stress cutoff using the Coulomb stress of $50 \mathrm{MPa}$ to approximate the plastic failure in our model. The Coulomb stress is computed from stresses which are inferred from the computed strain rates (Equation 4). We analyze predicted folding where the Coulomb stress is lower than $50 \mathrm{MPa}$, which is spatially $>\sim 100 \mathrm{~km}$ east of the plate boundary.

Before breakup (at $\sim 56 \mathrm{Ma}$ ), the relatively slow motion of the Greenland Plate results in moderate E-W contraction and formation of N-S oriented folds north of Sørkapp (Sk) (Figure 6a). In contrast, the southern part 
(a) Model M1 (65 Ma) - Favourites strikes

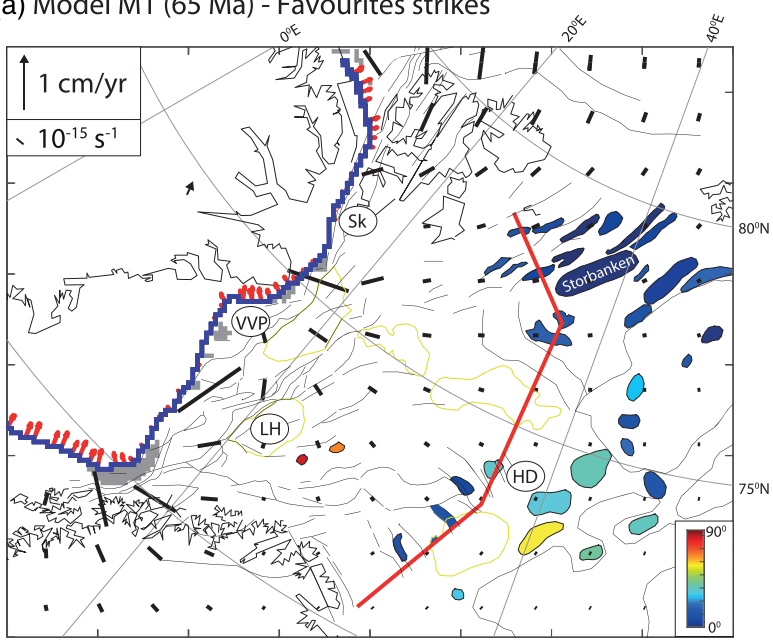

(b) Model M2 (65 Ma) - Favourite strikes

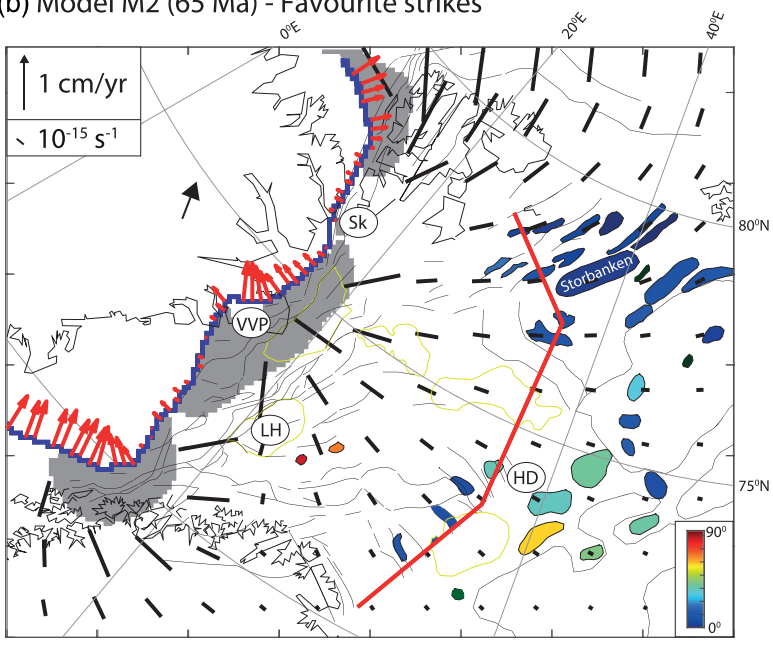

(c) Model M1 (52 Ma) - Favourite strikes

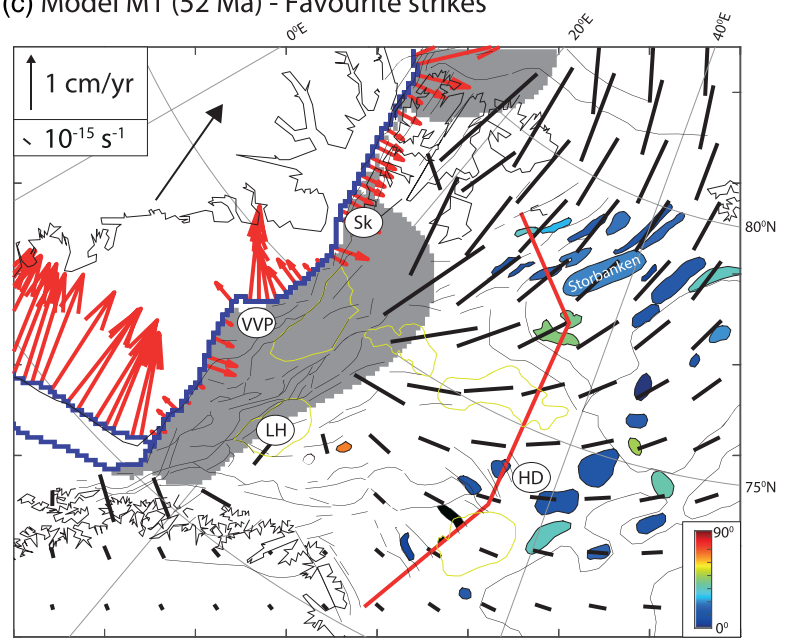

(d) Model M2 (52 Ma) - Favourite strikes

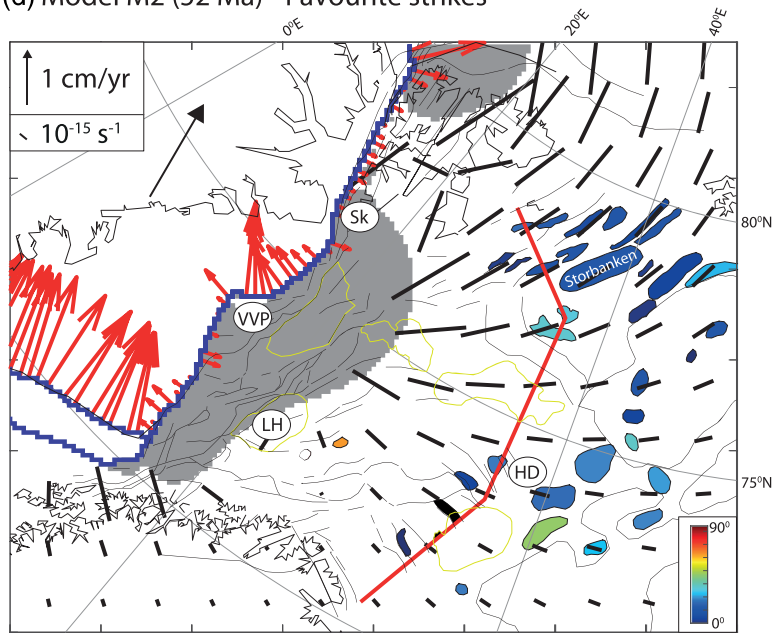

Figure 6. Predicted favored folds in the Barents Sea shelf during the latest Cretaceous-Eocene Greenland-Eurasia relative plate motions. The figure shows (a) the preferential direction of folding (black streaks) at $65 \mathrm{Ma}$ in a box restricted to the Barents shelf for model M1, (b) the preferential direction of folding at $65 \mathrm{Ma}$ in the Barents Sea shelf for model M2, (c) the preferential direction of folding at $52 \mathrm{Ma}$ in the Barents Sea shelf for model M1, and (d) the preferential direction of folding at $52 \mathrm{Ma}$ in the Barents Sea shelf for model M2. The length of the streak is proportional to the amplitude of growth rate $\alpha$. The black arrow represents the Greenland Plate velocity vector. The red arrows represent the normal velocity applied at the Greenland-Eurasia boundary. The gray areas represent zones with Coulomb stress larger than $50 \mathrm{MPa}$. The rainbow shades represent the deviation angle (in ${ }^{\circ}$ ) between the modeled fold axes and the observed anticline axes. HD: Haapet Dome, LH: Loppa High, Sk: Sørkapp, VVP: Vestbakken Volcanic Province.

of the incipient continental margin is subject to extension (future Vestbakken margin [VVP]). The resulting modeled fold distribution exhibits a regional pattern radiating from the Vestbakken area with fold axes oriented NNE east of Svalbard. The modeled fold axes progressively rotate to SE oriented folds in the SE Barents Sea. The angular deviation of the predicted and the observed fold axes amounts to less than $10^{\circ}$ in the north as well as in the south indicating a good agreement (Figure 6a).

After breakup and during the early seafloor spreading in the northeast Atlantic (56-47 Ma), Greenland roughly keeps the same bearing and hence the regional fan-shaped fold pattern is preserved (Figure 6c). The difference compared to the prebreakup period is that Greenland dramatically accelerates and the accentuated push against northern Eurasia causes larger N-S oriented cylindrical folds in the north, roughly parallel to the plate boundary. Also, intensified extension south of Sørkapp leads to larger extensional strain rates and stresses in a wider area along the future southwestern Barents Sea margin. As a result, the amplitude of folds decreases from north to south. The NNE oriented large folds in the north gently rotate to SE smaller folds in the SE Barents Sea (Figure 6c). The modeled cylindrical folds in the north have a general 
strike close to the mean trend of the observed elongated anticlines and inverted Paleozoic half-grabens east of Svalbard; there, the angular deviation between the predicted and the observed fold axes is less than $10^{\circ}$ albeit the deviation is more pronounced south of Storbanken. In the Norwegian SE Barents Sea, the direction of favored folds is also in good agreement (deviation less than $10^{\circ}$ ) with the NW-SE direction at the observed fold structures. After $52 \mathrm{Ma}$, the continuous widening of the North Atlantic oceanic domain prevents folding in the southern Barents Sea. Contemporaneously, the northward retreat of the restraining bend north of Svalbard and the reestablishment of a transtensional regime prevent folding in the northern Barents Sea as well. Folding becomes confined to a smaller area of the western Barents Sea located between the Loppa High (LH) and Sørkapp (see Figure S4c in the supporting information for the model results at time $45 \mathrm{Ma}$ ).

\subsubsection{Model M2}

The second plate kinematic model, M2 slightly differs from M1 (Figure 4). Before breakup, from 78-69 Ma (Phase 1, subphase a) Greenland slowly moves $(\sim 0.1 \mathrm{~cm} / \mathrm{yr})$ eastward orthogonal to Eurasia margin. Then from $69-56 \mathrm{Ma}$ (Phase 1, subphase b), it moves faster $(\sim 0.5 \mathrm{~cm} / \mathrm{yr})$ northwestward starting to establish a strike-slip/transpression regime with the (future) western margin of the Barents Sea shelf. After breakup at $56 \mathrm{Ma}$ (Phase 2 subphase a), there is a strong component of transtension (at $\sim 1.8 \mathrm{~cm} / \mathrm{yr}$ ) which shifts to a robust strike-slip/transpression regime (at $\sim 2 \mathrm{~cm} / \mathrm{yr}$ ) from 52 to $48 \mathrm{Ma}$ (Phase 2 subphase b), after which a moderate transtensional northwestern motion is resumed like for model M1 (Phase 2 subphase c). During these times, the model also predicts an overlap of Greenland and the Barents Sea shelf, though it is less pronounced than for M1 (Figure 4).

This alternative plate kinematic model gives roughly similar fan-shaped folding patterns to M1 albeit some differences before $49 \mathrm{Ma}$. Before breakup, stronger transpression compared to M1 causes more pronounced folding with NNE oriented folds in the north progressively turning to SE oriented folds in the southeast Barents Sea (Figure 6b). The angular deviation between the predicted and the observed fold axes amounts to less than $10^{\circ}$ in the north as well as in the south indicating a general very good agreement. Immediately after breakup the strong transtensional regime causes major extension orthogonal to the western margin, accompanied with contraction sub parallel to the margin (see Figure S4b in the supporting information for the model results at time $55 \mathrm{Ma}$ ). Later, at $52 \mathrm{Ma}$, a transpressional regime similar to M1 is reestablished, giving rise to NNE oriented large folds in the north turning into smaller amplitude SE oriented folds in the southern part of the model, matching the observed pattern of contraction (Figures 6d). In general, the agreement between modeled fold axes in model M2 and the observed orientation of elongated anticlines is slightly better than that for model M1, especially in the northern Barents Sea. The average deviation angle between the modeled fold axes and the observed anticline axes is $29^{\circ} 19$ for M1 while it is only $23^{\circ} 43$ for M2 at $52 \mathrm{Ma}$.

\subsection{Results Along the Regional Profile}

We sampled the computed relative fold growth rate $\alpha$ along the regional profile shown in Figure 1, crossing the Norwegian Barents Sea from north to south (Figure 7). North of the Olga Basin $\left(77^{\circ} \mathrm{N}\right)$, the trend of faults and lineaments associated with the structure of crystalline basement is roughly SW-NE to SSW-NNE, following the general trend of the mid-Carboniferous rifts within the Caledonian domain (Faleide et al., 2008; Grogan et al., 1999). Southward structures are NW-SE oriented following the Timanian structural trend (Faleide et al., 2018; Hassaan et al., 2020; Klitzke et al., 2019; Riztmann \& Faleide, 2009).

Contrary to the previous approach in sections 4.1 and 4.2, the strikes of initial perturbations are set and they are set according to the strikes of the observed inverted structures. Hence, we compute the relative fold growth rate $\alpha$ assuming that initial perturbations are oriented SSW-NNE north of $77^{\circ} \mathrm{N}$, and oriented NW-SE south of $77^{\circ} \mathrm{N}$ (Figure 7). For model M1 (Figure 7a), folding is generally predicted in the northern and southern domains. During prebreakup Phase 1, the slow transpression motion of Greenland causes weak folding along the entire transect. After breakup (Phase 2), acceleration of the Greenland Plate during subphase a causes stronger NNE oriented folding in the north of $77^{\circ} \mathrm{N}$ and NW oriented folding south of $77^{\circ} \mathrm{N}$ except north of the Olga Basin. After $50 \mathrm{Ma}$, folding wanes in the south because the North Atlantic oceanic domain is progressively widening preventing conveying of stress in the SW Barents Sea. The migration of the restraining bend toward the axis of oblique seafloor spreading in the north later combined with a change to a transtensional regime (at 47-48 Ma) prevent folding in the northern Barents Sea shelf as well. 
(a) Model M1
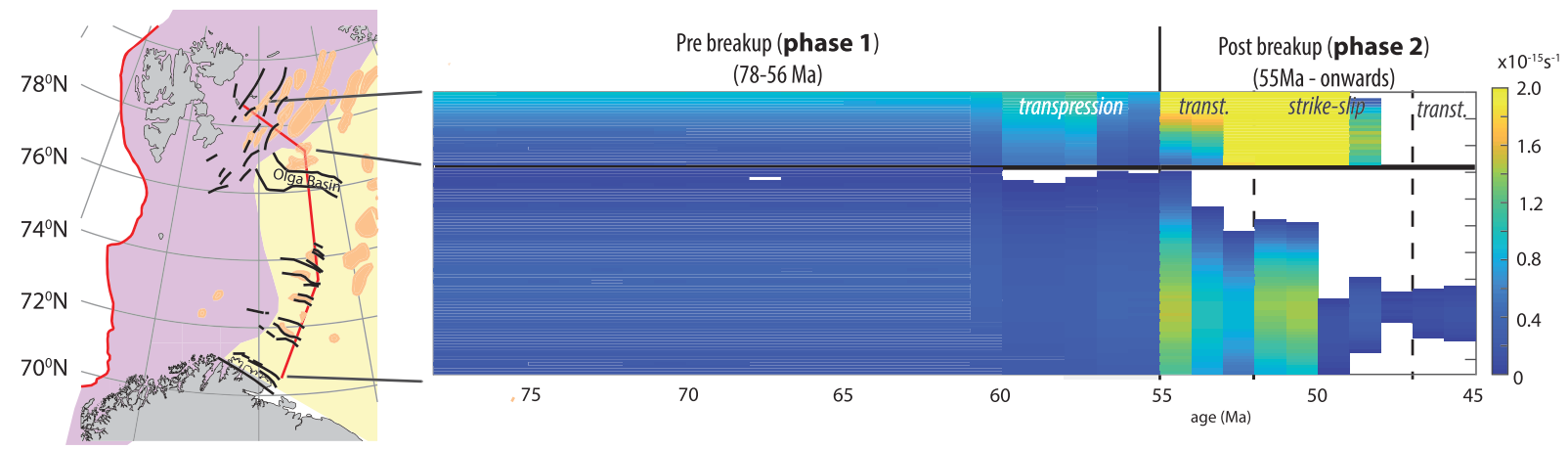

\section{(b) Model M2}
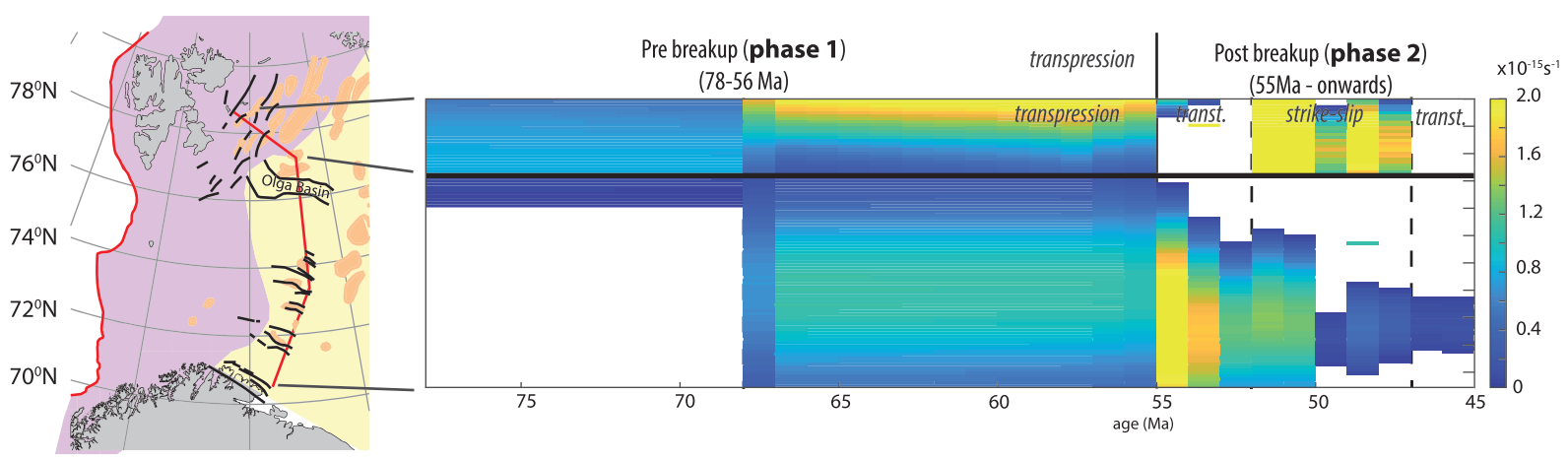

\section{(c) Model M2 with GPE}
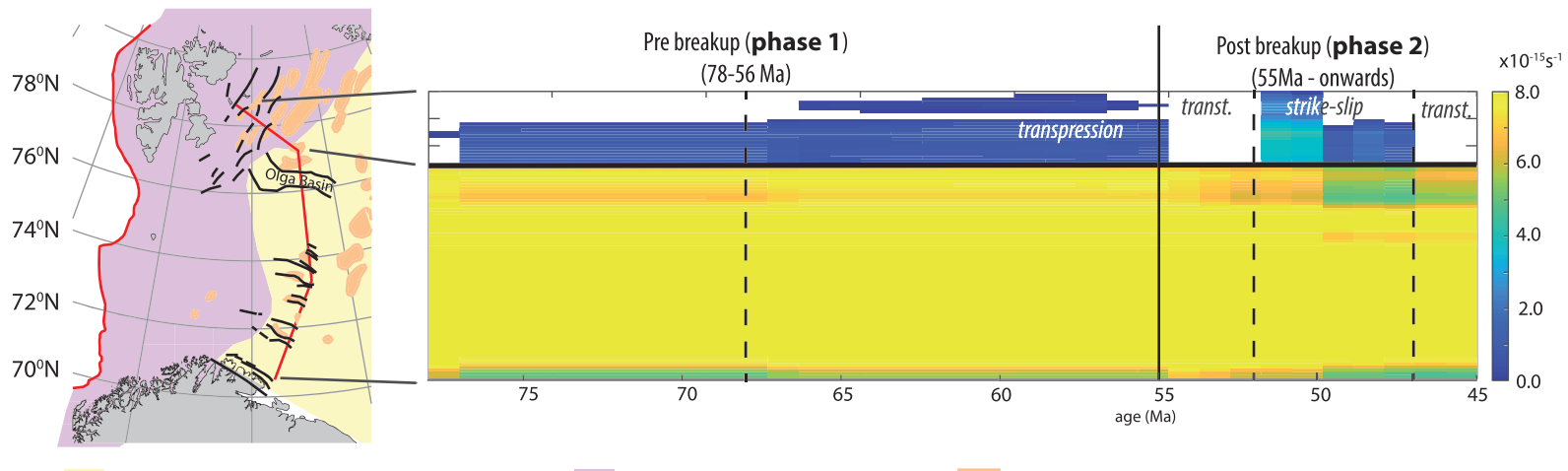

Timanian trend (after Klitzke et al., 2019)

Caledonian trend

Anticlines and domes

Figure 7. The latest Cretaceous-Eocene evolution of fold growth rate $\alpha$ (colors) along the regional transect crossing the Central Barents Sea from north to south The figure shows (a) the modeled fold growth rates $\alpha$ for model M1, (b) the modeled fold growth rates $\alpha$ for model M2, and (c) the modeled fold growth rates $\alpha$ for model M2 with GPE-related stresses along the transect (vertical axis) and through time (horizontal axis). White gaps correspond to negative rate $\alpha$. The transect is segmented in two domains north of $77^{\circ} \mathrm{N}$; and south of $77^{\circ} \mathrm{N}$. it is assumed that initial perturbations are NE-SW to NNW-SSE oriented north of $77^{\circ} \mathrm{N}$, and NW-SE oriented south of $77^{\circ} \mathrm{N}$. the maps show the distribution of faults (black lines), inverted structures (brown), and basement domains (Caledonian in purple, Timanian in yellow).

Overall, model M2 (Figure 7b) predicts folding in the Timanian domain as well as in the Caledonian domain. Before breakup (Phase 1), folding is initially predicted only in the Caledonian domain. After $68 \mathrm{Ma}$, the predicted oblique convergence of Greenland against Eurasia causes mild folding in both the Caledonian and Timanian domains. Immediately after breakup, Greenland drifts away from Eurasia creating a transtensional regime that is continuous along the entire Greenland-Eurasia boundary. This gives rise 
to EW and NW-SE oriented folds, suborthogonal to the continental margin. Folding is limited to the Timanian domain where basement faults are almost perpendicular to the contraction direction. In contrast, in the north, basement faults form a low angle with the direction of contraction, hence no reactivation of folding is predicted. After $52 \mathrm{Ma}$, the kinematics of the Greenland Plate in models M1 and M2 is the same (Figure 4). A strike-slip/transpression regime is reestablished allowing for NNE oriented folding in the northern Barents Sea and SE oriented folding in the south. Folding then almost entirely disappears once mild transtension is renewed at 47-48 Ma.

\section{Discussion}

\subsection{Summary of Results}

We use a thin-sheet viscous approximation of the Barents Sea lithosphere to compute the intraplate strain rate caused by oblique collision of Eurasia and the Greenland Plate in the latest Cretaceous-Eocene times. An analytical solution for 3-D folding is used to predict the growth of initial perturbations due to inherited structures in the crystalline basement (faults and grabens).

In the first series of numerical experiments, we look at the mechanical effects of a rounded rigid indenter pushing against a thin-sheet viscous model of Eurasia. The model predicts folding is preferentially $\mathrm{N}-\mathrm{S}$ oriented in most of the Barents Sea shelf (Figure 5b). In the case of obliquely oriented indenter, folding is confined to the northeastern part of the model and favored strikes are dominantly NW-SE to N-S oriented (Figure 5d). With "no shear" boundary conditions, oblique compressive forcing at the boundary causes strong rotation of favored folds in the model, from N-S oriented in the north to SW-NE oriented further south, that is, folds are roughly tangent to the indenter in most of the Barents Sea shelf and suborthogonal to the indenter along the Norwegian margin (Figure $5 \mathrm{f}$ ). The size of the deformed region is controlled by the radius of the indenter ( $600 \mathrm{~km}$ in our model).

In the second series of models, a thin-sheet viscous model of Eurasia is combined with two Cretaceous-Eocene plate kinematic models, which predict roughly similar folding patterns. For postbreakup times, the general strike-slip regime for both models M1 and M2 favors NNE-SSW-oriented folds in the north rotating to NW-SE-oriented folds in the southern Barents Sea, in accordance with the observed contraction (Figures $6 \mathrm{c}$ and $6 \mathrm{~d}$ ). After $50 \mathrm{Ma}$, widening of the North Atlantic oceanic domain adjacent to SW Barents Sea shelf combined with retreat of the restraining bend north of Svalbard dramatically limits folding, first in the south then in the north.

Finally, the growth of folds above heterogeneities following observed NNE oriented Caledonian trend in the north and NW oriented Timanian trend in the south is computed along a regional profile crossing the Barents Sea shelf from north to south. Both models M1 and M2 predict mild folding in the Timanian domain immediately after breakup followed by robust folding in the Caledonian domain later in the Eocene (Figures 7a and 7b).

The timing of the predicted folding must be handled with care because the timing of postbreakup phases for the two published plate reconstruction models contradict some observables, especially the observed Eocene contraction at Svalbard, and they may disagree with other published studies (Piepjohn et al., 2016). In addition, the published kinematics of prebreakup late Cretaceous phase is uncertain. However, the goal of the paper is to evaluate a numerical method to predict intraplate deformation caused by the interactions of Greenland with Eurasia in the latest Cretaceous-Eocene times.

\subsection{The Contributions of GPE Gradients.}

This paper focuses on deformation caused by tectonic forces at plate boundaries related to interactions of Greenland with Eurasia in the Paleogene. Other contributions have been neglected. Those contributions include horizontal gradient of GPE (Coblentz et al., 2015; Ghosh et al., 2008; Schiffer \& Nielsen, 2016), and horizontal tractions at the base of the lithosphere related to mantle convection (Ghosh et al., 2008).

Lithospheric GPE gradients in the North Atlantic, arising from elevated areas (such as mid-ocean ridges and Iceland), and lithosphere density contrasts, as well as from radial tractions (dynamic uplift) caused by the Iceland plume impingement and mantle motions in the North Atlantic, may contribute to intraplate 
deviatoric stresses and deformation at North Atlantic continental margins, including the Barents Sea shelf (Coblentz et al., 2015; Doré et al., 2008; Schiffer \& Nielsen, 2016).

We here estimate the contribution of lithospheric GPE gradients in the North Atlantic to deformation in the Barents Sea shelf. We have no access to GPE distribution in Paleogene. However, we can estimate the deformation caused by present-day GPE gradients, which can in turn give us some clues about the paleo-situation.

Following the results of Gac et al. (2016), we calculate the present-day lateral GPE variations from the 3-D density model of lithosphere in the Barents Sea-Kara Sea region published by Klitzke et al. (2015). The 3-D density model is constrained by seismic data, topography, and gravity signal. The GPE gradient is estimated with respect to a standard Mid-Ocean Ridge reference lithosphere column. We do not consider Iceland as reference column because the Iceland insular margin probably originated later than Paleogene, that is, in Miocene times following a major magmatic event (Doré et al., 2008; Ellen, 2002). The extracted GPE gradient corresponds to an average compressional force magnitude of $\sim 10^{13} \mathrm{~N} \mathrm{~m}^{-1}$ in the central Barents Sea (Gac et al., 2016).

We use the approach described in Lechmann et al. (2011), to add the GPE gradient as a source term in our thin sheet model assuming $200 \mathrm{~km}$ as reference depth (see section 3.1).

Similar to the previous set, models were run with the viscosity of $5 \times 10^{22} \mathrm{~Pa}$ s for the continents. The present-day GPE distribution causes in general SSW-NSE to N-S oriented contraction $\left(\sim 10^{-16} \mathrm{~s}^{-1}\right)$ in the most of the Barents Sea shelf (Figure 8b). These directions are consistent with measured stress directions in the SW Barents Sea (Fejerskov et al., 2000; Heidbach et al., 2018). In the central Barents Sea, south of the Olga Basin, the GPE-related extension is negligible (Figure 8b). However, the GPE-related contraction has almost the same orientation and magnitude as the tectonic contraction (Figure 8c) This yields amplified total contraction (Figure 8d) leading to markedly magnified folding rates in the Timanian domain (Figure 7c) compared to the model with no GPE (Figure 7b). However, further north, the GPE related extension is much larger and it has the same orientation as the tectonic contraction causing weakened total contraction in the Caledonian domain (Figure 8d)) and reduced folding rates compared to model M2 (Figure 7b).

To reiterate, these results must be handled with care because the GPE gradient is estimated for the present day. In Paleogene, the regional lithosphere structure was probably different; for example, there was no elevated oceanic ridge and oceanic domain separating Greenland and Eurasia (e.g., Gaina et al., 2009), and Svalbard was less elevated due to Miocene preglacial tectonic uplift (Dörr et al., 2013). So, it is likely that GPE gradient was probably smaller. In addition, the compressional force computed from the 3-D density model of Klitzke et al. (2015) may be an overestimation. Indeed, filtered geoid anomaly data for the North Atlantic region rather suggest a compressional force ranging from $10^{12}$ to $2 \times 10^{12} \mathrm{~N} . \mathrm{m}^{-1}$ in the Barents shelf (Gac et al., 2016), that is 2 to 4 times smaller than the compression caused by our computed GPE gradient. Hence, the contribution of GPE to deformation would probably be less dramatic and more moderate compared to tectonic forces.

\subsection{The Contribution of Mantle Tractions}

In our modeling, we also neglect the possible contribution of mantle convection-driven horizontal tractions at the base of the lithosphere. Several other authors have estimated this contribution. Ghosh et al. (2008) estimated the contribution to global surface deviatoric stress of both GPE (that includes lithosphere density driven buoyancy forces and dynamic topography) and basal horizontal tractions caused by mantle convection. They tested several models characterized by varying viscosity contrast between lithosphere and asthenosphere. Their favorite models (with large viscosity contrast) predict that horizontal tractions dominate over GPE in zones such as western United States and Tibetan Plateau, marked by large lateral density contrast created by subducting slabs.

Our zone of interest, the North Atlantic area was located far from subducting slabs in the Paleogene (Shephard et al., 2014), suggesting horizontal tractions there have minimal effects on deviatoric stresses compared to GPE and tectonic forces. It is therefore reasonable to neglect horizontal tractions in our modeling. 
(a) Present-day GPE

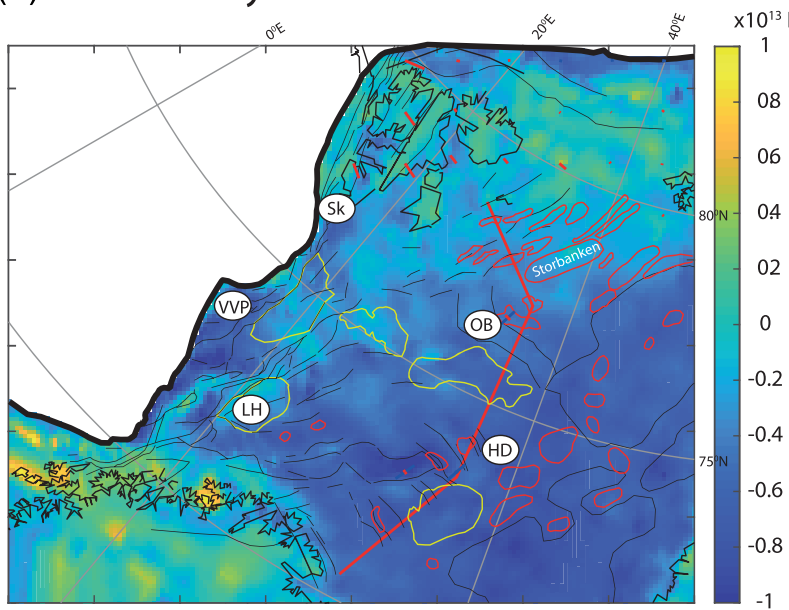

(c) Model M2 strain rates

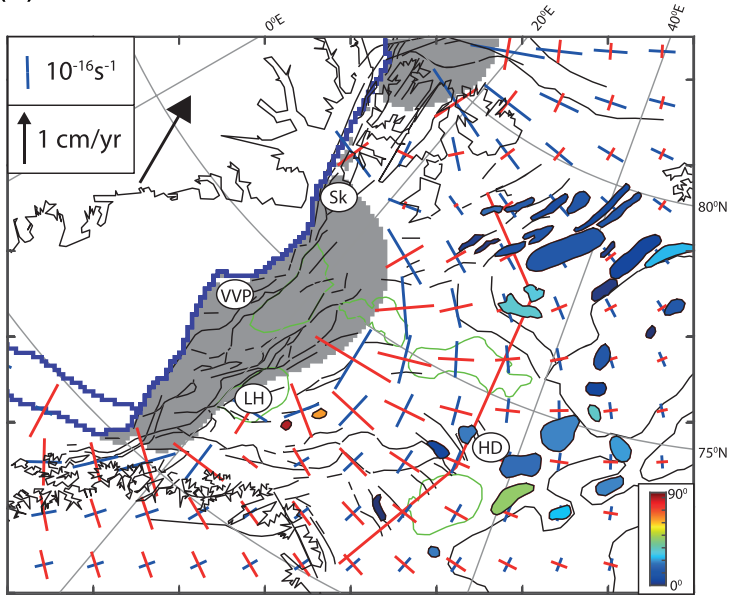

(b) Present-day GPE strain rates

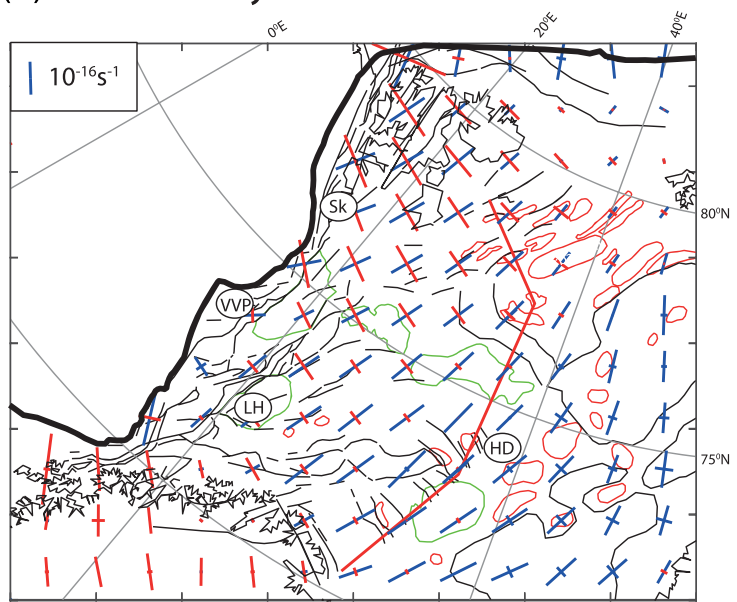

(d) Model M2 with GPE strain rates

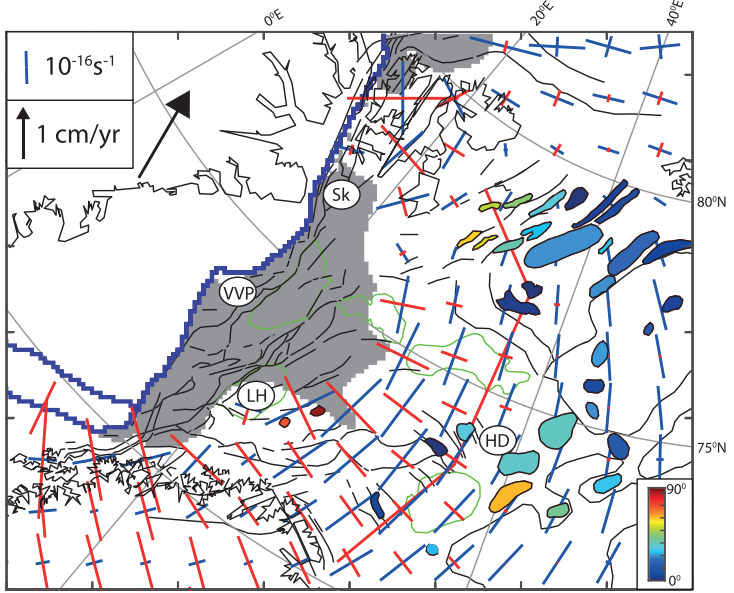

Figure 8. Modeled strain rates. The figure shows (a) the gravitational potential energy (GPE) extracted from the 3-D density model of Klitzke et al. (2015) for the Barents Sea-Kara Sea region, (b) the principal strain rates caused by the GPE, (c) principal strain rates caused by collision of Greenland with Eurasia for model M2 at $52 \mathrm{Ma}$, and (d) principal strain rates combining the contributions of GPE gradients and of the collision of Greenland with Eurasia for model M2 at $52 \mathrm{Ma}$. Red lines represent extension and blue lines represent compression. The gray areas represent zones with Coulomb stress larger than $50 \mathrm{MPa}$. The thin red line shows the location of the seismic transect. HD: Haapet Dome, LH: Loppa High, OB: Olga Basin, Sk: Sørkapp, VVP: Vestbakken Volcanic Province.

\subsection{Reconciling the $40 \mathrm{~km}$ Shortening Across the Svalbard Fold-and-Thrust}

We have estimated the horizontal displacement accumulated in Svalbard during the latest CretaceousEocene transpression of Greenland against the western margin of Svalbard for models M1 and M2 (Figure 9). The cumulative displacement is calculated by the summation of incremental displacements over a series of instantaneous models during the period of time 78-45 Ma assuming a constant time increment of 1 Myr. It is calculated along three transects crossing north, central, and south Svalbard in a direction perpendicular to the western margin of Svalbard. Both models, M1 and M2, predict that the transpression of Greenland against the western margin of Svalbard causes a regional eastward displacement of the northern Barents Sea shelf and the displacement is foremost focused on Svalbard. For the three profiles, the displacement is the largest on the western margin of Svalbard and rapidly decreases eastward. For both models, the maximum displacement achieved is more than $50 \mathrm{~km}$ in northwestern Svalbard and decreases down to 10$20 \mathrm{~km}$ toward Sørkapp (South transect). Those numbers are close to the $\sim 40 \mathrm{~km}$ shortening estimate based on geological observations (Bergh et al., 1997). For model M1 most of the shortening occurs after breakup. However, for model M2, the predicted stronger prebreakup strike-slip/transpression phase ensures that shortening occurs mostly before breakup. After breakup, the modeled robust transtension along Svalbard (Figure S4b) reduces the amount of prebreakup shortening (see the central transect on Figure 9b). 
(a) Model M1 - cumulative displacement (km)
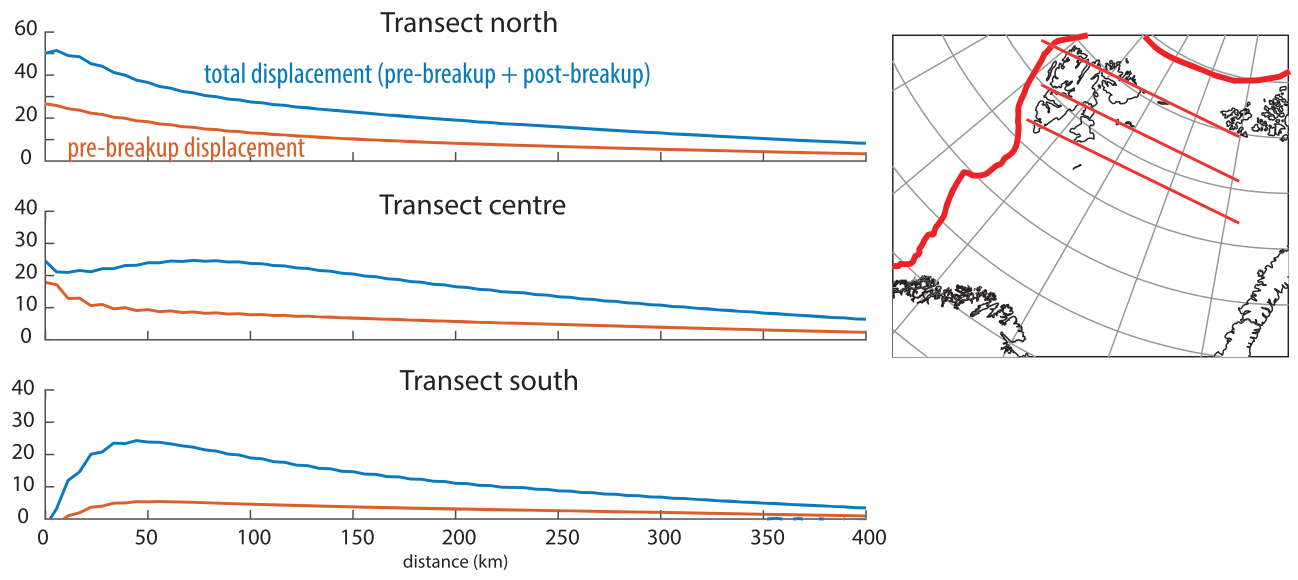

\section{(b) Model M2 - cumulative displacement (km)}
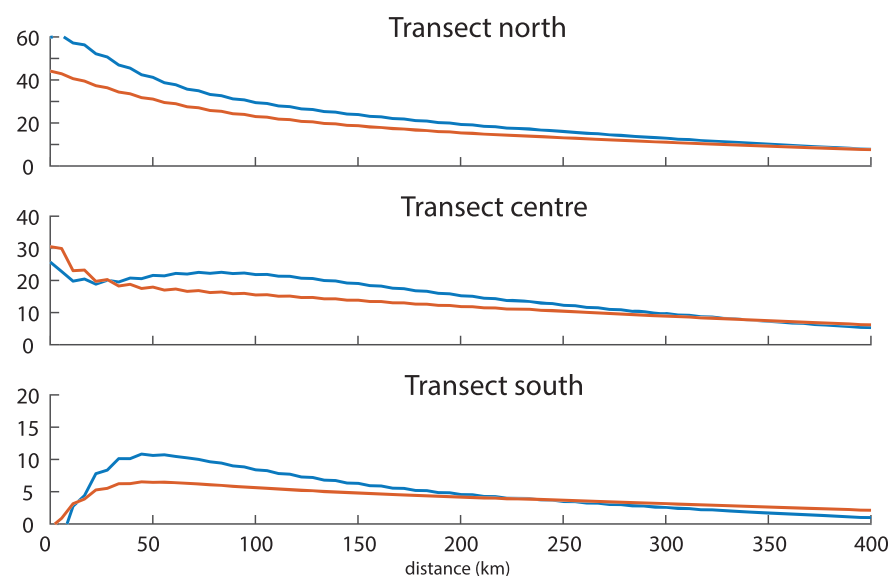

Figure 9. Cumulative displacement in the northern Barents Sea shelf during the latest Cretaceous-Eocene: (a) Model M1 and (b) Model M2. The figures show the horizontal displacement accumulated in a direction perpendicular to the western Svalbard margin along three transects crossing Svalbard from north to south. The red curves indicate the prebreakup cumulative displacement and the blue curves represent the total (prebreakup + postbreakup) cumulative displacement.

\subsection{The Geometry of the Greenland-Eurasia Boundary-Key Controlling Parameter}

Fold orientation within the Barents Sea shelf is controlled by applied velocity at the Greenland-Eurasia boundary, which is in turn controlled by the angle between the Greenland Plate velocity vector and the local tangent to the boundary. Because the Greenland Plate velocity vector is homogeneous across the plate, the fold orientation is mostly determined by the curvature of the Greenland-Eurasia boundary: The Vestbakken releasing bend causes fan-shape fold pattern centered on Bjørnøya.

During its overall northward migration, the direction of the Greenland Plate velocity changes. Those changes are nonetheless moderate and therefore the fold distribution is still controlled by the curvature of the Greenland-Eurasia boundary, and it retains the same fan-shaped pattern through model time (Figure 10a).

Following Greenland's northward retreat, the restraining bend in the north vanishes at $51 \mathrm{Ma}$, and the northern segment of the Greenland-Eurasia boundary becomes a straight line (Figure 10b). There the applied normal velocity becomes solely determined by the direction of the Greenland Plate. The change to transtension at $47 \mathrm{Ma}$ gives normal extension all along the northern segment of the boundary, restricting folding in the northern Barents Sea shelf (Figure 10c). In the south, breakup in the North Atlantic at $56 \mathrm{Ma}$ creates a weaker and widening oceanic domain, which locally decouples Greenland from Eurasia. This prevents stresses being conveyed into the SW Barents Sea, limiting deformation and folding. 
(a) Favourite strikes - $56 \mathrm{Ma}$

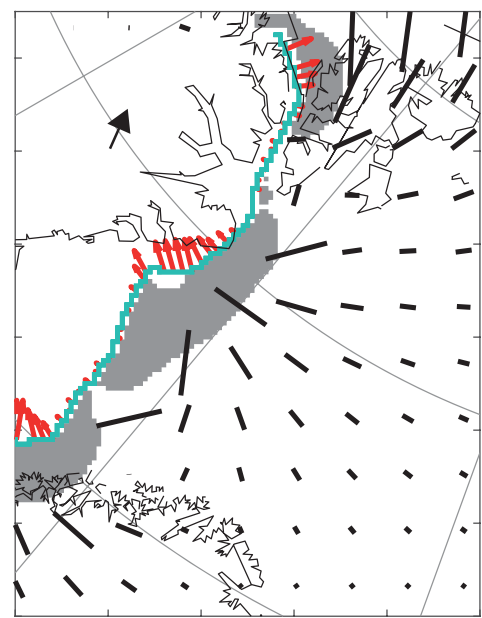

(b) Favourite strikes - $51 \mathrm{Ma}$

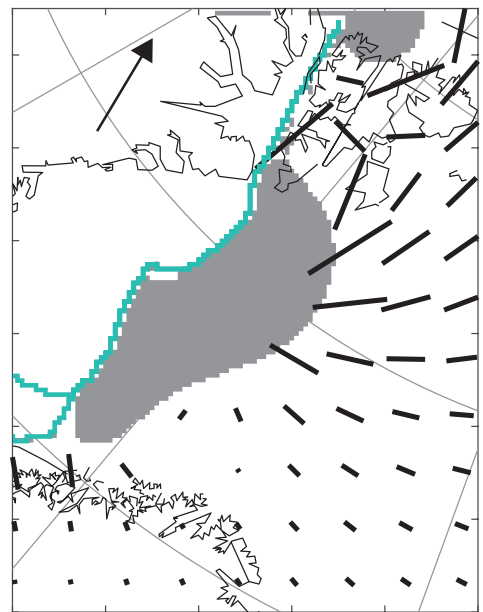

(c) Favourite strikes - $45 \mathrm{Ma}$

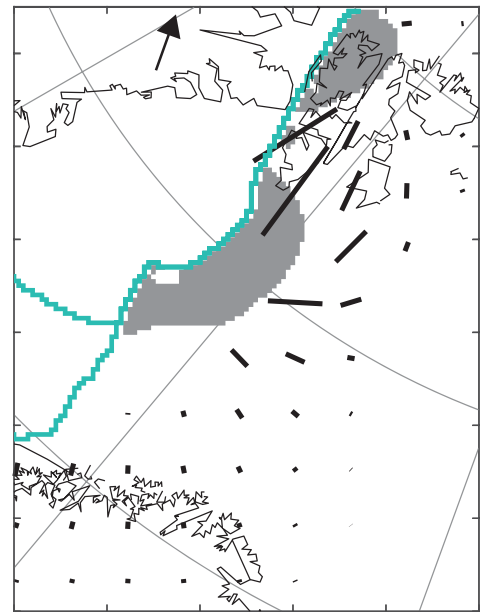

Figure 10. Modeled Greenland-Eurasia kinematics in the Paleogene (a) at $56 \mathrm{Ma}$, (b) at $51 \mathrm{Ma}$, and (c) at $45 \mathrm{Ma}$. The favored fold strikes are computed for plate kinematic model M2 and are shown at these three time periods. The length of the streak is proportional to the amplitude of growth rate $\alpha$. The black arrow represents the Greenland plate velocity vector. The red arrows represent the normal velocity applied at the Greenland-Eurasia boundary. The gray areas represent zones with Coulomb stress larger than $50 \mathrm{MPa}$.

The geometry of the Greenland-Eurasia boundary through time is thus a key controlling parameter in these models. However, it is somewhat uncertain despite being approximately (and variably) delineated in regional plate models (e.g., Barnett-Moore et al., 2018; Faleide et al., 2008). Therefore, for the sake of simplicity, our Greenland-Eurasia boundary is assumed to be linear and regular. It only reproduces the large-scale obvious releasing and restraining bends (such as south of Sørkapp). However, the (present-day) COB is marked by a succession of restraining and releasing bends, at smaller and larger scales, like, for example, along the Senja Fracture Zone (SFZ on Figure 1a). The presence of such small-scale irregularities is expected to affect the stress and deformation pattern only locally, along the western margin of the Barents Sea. They will not modify the first order results.

\subsection{Latest Cretaceous-Paleogene Plate Motions and Uncertainties in the Kinematic Models} 5.6.1. Differences With the Conceptual Model of Piepjohn et al. (2016)

The timing of postbreakup phases for the two published digital plate reconstruction models (e.g., BarnettMoore et al., 2018) may disagree with other regional published studies (Piepjohn et al., 2016) and contradict some observables, especially the observed Eocene contraction at Svalbard.

Piepjohn et al. (2016) proposed a two-phase conceptual model based on the analysis of oceanic magnetic anomalies and geologically observed contraction across the Canadian Arctic Islands, Greenland, and Svalbard (Figure 2).

The two published kinematic models within Euler rotations somewhat disagree with this scenario. They both propose breakup at anomaly 24, like Piepjohn et al. (2016), but use a timescale which sets this time to $56 \mathrm{Ma}$. From 56 to $53 \mathrm{Ma}$, they predict a short phase of transtension, in contradiction with Piepjohn et al. (2016). However, after $53 \mathrm{Ma}$, the two kinematic models agree better with the conceptual model of Piepjohn et al. (2016). Indeed, from 53 to $47 \mathrm{Ma}$, they both predict strike-slip/transpression and end of strike-slip/transtension as Greenland begins to move NW after $47 \mathrm{Ma}$.

\subsubsection{Latest Cretaceous Plate Motions}

Both models, M1 and M2, propose that a transpressional regime was established long before breakup (at least from $78 \mathrm{Ma}$ ) which causes deformation across the Barents Sea shelf and Svalbard (Figure 9). The models predict that the pre-Paleocene deformation is weak and the culmination of intraplate deformation is postbreakup (according to M1) or that contraction at Svalbard is mostly pre-Paleocene (according to M2).

Note that these pre-Cenozoic model results must be handled with caution because the latest Cretaceous kinematics within the North Atlantic are uncertain due to the regional kinematics not being constrained 
by clear magnetic anomalies (or debated lineaments within the Labrador Sea). Furthermore, the North Atlantic underwent multiphase rifting for an extended period of time (over 300 Myr) after postCaledonide collapse (e.g., Abdelmalak et al., 2019; Faleide et al., 2008; Skogseid et al., 1992)—the consequences of which for the Barents Sea shelf remain to be reconciled with future work on circum-Greenland motions. On the other hand, mechanical modeling results offer quantitative predictions that can be tested against field observations to improve the existing kinematic models.

\section{Conclusions}

We develop a numerical approach, combining plate kinematics and mechanical models of lithospheric deformation, to predict intraplate the deformation caused by the Greenland Plate motion relative to Eurasia in latest Cretaceous-Eocene times. We estimate the preferred orientations of folds using a 3-D analytical solution for folding. Two alternative published plate kinematic models for the GreenlandEurasia-North America plate system are considered from 78-45 Ma. Our main findings are summarized in the following:

1. Rounded indenter models with continuous boundary conditions at the Eurasia indenter boundary predict N-S to NW-SE oriented folds in most of the Barents Sea shelf. The size of the deformation zone is controlled by the radius of the indenter $(\sim 600 \mathrm{~km})$.

2. Rounded indenter models with a "no shear" Eurasia-indenter boundary predict favored folds that are roughly parallel to the indenter boundary across most of the Barents Sea shelf. They are N-S oriented in front of the indenter to SW-NE oriented further south.

3. The two tested plate kinematic-consistent models M1 (based regionally on Barnett-Moore et al., 2018; Gaina et al., 2009) and M2 (based on Gaina et al., 2009; Roest \& Srivastava, 1989) show that the Greenland Plate's general north to northwestward sliding motion promotes anticlines in the entire Barents Sea shelf. Stresses, deformation, and folding are the largest in the northern Barents Sea and decrease southtward.

4. Following breakup at $56 \mathrm{Ma}$, widening of the nascent North Atlantic Ocean progressively inhibits folding in the southern Barents Sea. Folding in the northern Barents Sea wanes later in the Eocene following the destruction of the Eurekan restraining bend. The culmination of folding in the Barents Sea corresponds to the major reorganization of plate motion in the northeast Atlantic marked by the onset of seafloor spreading between the Eurasia and Greenland lithospheric plates.

5. Both models predict that the preferential direction of fold axes is generally SSW-NNE in the northern Barents Sea and progressively rotates to NW-SE in the southern Barents Sea in good accordance with the observed contraction axes east of Svalbard and in the SE Norwegian Barents Sea. Thus, the observed fan-shaped pattern of elongated anticlines and inverted Paleozoic half-grabens in the Barents Sea reflects the overall geometry of the plate boundary during the Eurekan Orogeny, and does not require several contractional events to be invoked as explanation.

6. We quantified the effect of inherited oriented basement heterogeneities in the nucleation of folding by analyzing the relative fold growth rate along a regional NS seismic transect. Both models M1 and M2 predict mild folding in the Timanian basement domain that may start immediately after the continental breakup at $\sim 56 \mathrm{Ma}$, followed by robust reactivation folding in the Caledonian domain later in the Eocene (56-47 Ma). The model M2 predicts compressive deformation regime in the Svalbard region occurred during a prolonged period extending into the late Cretaceous ( $68 \mathrm{Ma})$.

7. A new improved model of North Atlantic-Arctic plate kinematics in the Cenozoic should incorporate the predictions of mechanical modeling to accurately constrain the timing of intraplate deformation within the entire Eurekan orogen.

\section{Data Availability Statement}

The GPlates-compatible rotation files for the two published Greenland plate kinematic models M1 and M2 are provided in the supporting information file. The rotation file for M1 is based on kinematic reconstructions of Müller et al. (2016). Data can be downloaded from this site (https://www.annualreviews.org/doi/ suppl/10.1146/annurev-earth-060115-012211). The rotation file for M2 is based on kinematic reconstructions of Seton et al. (2012). Data sets for this research are included in this paper: Seton et al. (2012). 
GPlates (http://www.gplates.org) can be downloaded on an open-source and cross-platform (Windows, Mac, and Linux) basis. The GPE distribution of the Barents and Kara region, from which the GPE gradients computation are based, is published in Gac et al. (2016). Data sets for this research are included in this paper: Gac et al. (2016).

\section{Acknowledgments}

The present work is part of the CEED Mod project and ARCEx (Research Centre for Arctic Petroleum Exploration), which is funded by industry partners. We also recognize the Research Council of Norway through its Centres of Excellence funding scheme, Project Number 223272. G. E. S. acknowledges support from VISTA -a basic research program in collaboration between the Norwegian Academy of Science and Letters, and Statoil (Project 6268, “DEFMOD”). Jakob Skogseid is thanked for constructive comments regarding the North Atlantic plate kinematic models. We thank Sergei Medvedev for constructive comments regarding the thin-sheet viscous model. We also thank Alexei Shulgin and Muhammad Hassan for their help in preparing the map on Figure 7.

\section{References}

Abdelmalak, M. M., Planke, S., Polteau, S., Hartz, E. H., Faleide, J. I., Tegner, C., et al. (2019). Breakup volcanism and plate tectonics in the NW Atlantic. Tectonophysics, 760, 267-296. https://doi.org/10.1016/j.tecto.2018.08.002

Barnett-Moore, N., Müller, D. R., Williams, S., Skogseid, J., \& Seton, M. (2018). A reconstruction of the North Atlantic since the earliest Jurassic. Basin Research, 30, 160-185. https://doi.org/10.1111/bre.12214

Barrère, C., Ebbing, J., \& Gernigon, L. (2009). Offshore prolongation of Caledonian structures and basement characterisation in the western Barents Sea from geophysical modelling. Tectonophysics, 470(1-2), 71-88. https://doi.org/10.1016/j.tecto.2008.07.012

Barrère, C., Ebbing, J., \& Gernigon, L. (2011). 3-D density and magnetic crustal characterization of the southwestern Barents shelf: Implications for the offshore prolongation of the Norwegian Caledonides. Geophysical Journal International, 184(3), 1147-1166. https:// doi.org/10.1111/j.1365-246X.2010.04888.X

Bergh, S. G., Braathen, A., \& Andresen, A. (1997). Interaction of basement-involved and thin-skinned tectonism in the tertiary fold-thrust belt of Central Spitsbergen, Svalbard. $A A P G, 81,637-661$.

Bird, P. (1999). Thin-plate and thin-shell finite-element programs for forward dynamic modelling of plate deformation and faulting. Computational Geosciences, 25(4), 383-394. https://doi.org/10.1016/S0098-3004(98)00142-3

Boyden, J. A., Müller, R. D., Gurnis, M., Torsvik, T. H., Clark, J. A., Turner, M., et al. (2011). Next-generation plate-tectonic reconstructions using GPlates. In G. R. Keller, \& C. Baru (Eds.), Geoinformatics: Cyberinfrastructure for the Solid Earth Sciences (9780521897150, pp. 95-114). Cambridge: Cambridge University Press.

Burov, E. B. (2011). Rheology and strength of the lithosphere. Marine and Petroleum Geology, 28(8), 1402-1443. https://doi.org/10.1016/j. marpetgeo.2011.05.008

Burov, E. B., Nikishin, A. M., Cloetingh, S. A. P. L., \& Lobkovsky, L. I. (1993). Continental lithosphere folding in Central Asia (part II): Constraints from gravity and tectonic modelling. Tectonophysics, 226(1-4), 73-87. https://doi.org/10.1016/0040-1951(93)90111-V

Chalmers, J. A. (1991). New evidence on the structure of the Labrador Sea/Greenland continental margin. Journal of the Geological Society of London, 148(5), 899-908. https://doi.org/10.1144/gsjgs.148.5.0899

Chalmers, J. A., \& Pulvertaft, T. C. R. (2001). Development of the continental margins of the Labrador Sea: A review. Special Publication. Geological Society of London, 187(1), 77-105. https://doi.org/10.1144/gsl.sp.2001.187.01.05

Cloetingh, S. A. P. L., \& Burov, E. B. (1996). Thermomechanical structure of European continental lithosphere: Constraints from rheological profiles and EET estimates. Geophysical Journal International, 124(3), 695-723. https://doi.org/10.1111/j.1365-246X.1996. tb05633.x

Cloetingh, S. A. P. L., \& Burov, E. B. (2011). Lithospheric folding and sedimentary basin evolution: A review and analysis of formation mechanisms. Basin Research, 23(3), 257-290. https://doi.org/10.1111/j.1365-2117.2010.00490.x

Cloetingh, S. A. P. L., Burov, E. B., \& Poliakov, A. (1999). Lithosphere folding: Primary response to compression? (from Central Asia to Paris basin). Tectonics, 18, 1064-1083.

Coblentz, D., van Wijk, J., Richardson, R. M., \& Sandiford, M. (2015). The upper mantle geoid: Implications for continental structure and the intraplate stress field. In G. R. Foulger, M. Lustrino, S. D. King (Eds.), The interdisciplinary Earth: A volume in honor of Don L. Anderson, Geological Society of America Special Paper 514 and American Geophysical Union Special Publication (Vol. 71, pp. 197-214). Tysons, USA: American Geophysical Union.

Cooper, M. A., Williams, G. D., de Graciansky, P. C., Murphy, R. W., Needham, T., de Paor, D., et al. (1989). Inversion tectonics-A discussion. In M. A. Cooper, \& G. D. Williams (Eds.), Inversion tectonics, Geological Society, London, Special Publications (Vol. 44, pp. 335-347). London: Geological Society.

Davy, P., \& Cobbold, P. R. (1991). Experiments on shortening of a 4-layer model of the continental lithosphere. Tectonophysics, 188(1-2), 1-25. https://doi.org/10.1016/0040-1951(91)90311-F

Dellmour, R.W., Stueland, E., Lindstrom, S., Tari, G., \& Purkis, S. (2016). The Håpet Dome in the Norwegian Barents Sea, Structural evolution and morphology of salt basins, 78th EAGE Conference \& Exhibition 2016, Vienna, Austria. Extended abstract, 6 p. https://doi. org/10.3997/2214-4609.201601647

Dimakis, P., Braathen, B. I., Faleide, J. I., Elverhoi, A., \& Gudlaugsson, S. T. (1998). Cenozoic erosion and the preglacial uplift of the Svalbard-Barents Sea region. Tectonophysics, 300(1-4), 311-327. https://doi.org/10.1016/S0040-1951(98)00245-5

Doré, A. G., Lundin, E. R., Kusznir, N. J., \& Pascal, C. (2008). Potential mechanisms for the genesis of Cenozoic domal structures on the NE Atlantic margin: Pros and cons and some new ideas. In H. Johnson et al. (Eds.), The nature and origin of compression in passive margins, Geological Society, London, Special Publications (Vol. 306, pp. 1-26). London: Geological Society.

Dörr, N., Clift, P. D., Lisker, F., \& Spiegel, C. (2013). Why is Svalbard an island? Evidence for two-stage uplift, magmatic underplating, and mantle thermal anomalies. Tectonics, 32, 473-486. https://doi.org/10.1002/tect.20039

Døssing, A., Hopper, J. R., Olesen, A. V., Rasmussen, T. M., \& Halpenny, J. (2013). New aero-gravity results from the Arctic: Linking the latest cretaceous-early Cenozoic plate kinematics of the North-Atlantic and Arctic Ocean. Geochemistry, Geophysics, Geosystems, 14, 4044-4065. https://doi.org/10.1002/ggge.20253

Ellen, S.M.O. (2002). Geological map, land and sea areas of northern Europe. Scale 1:4 million. Geological Survey of Norway.

England, P., \& McKenzie, D. (1982). A thin viscous sheet model for continental deformation. Geophysical Journal of Research and Astronomical Society, 70(2), 295-321. https://doi.org/10.1111/j.1365-246X.1982.tb04969.x

England, P. C. (1987). Diffuse continental deformation: Length scales, rates and metamorphic evolution. Philosophical Transactions. Royal Society of London, 321, 3-22.

England, P. C., Houseman, G., \& Sonder, L. (1985). Length scales for continental deformation in convergent, divergent, and strike-slip environments: Analytical and approximate solutions for a thin viscous sheet model. Journal of Geophysical Research, 90(B5), 3551-3557. https://doi.org/10.1029/JB090iB05p03551

Faleide, J. I., Bjørlykke, K., \& Gabrielsen, R. H. (2015). Geology of the Norwegian continental shelf. In K. Bjørlykke (Ed.), Petroleum geoscience: From sedimentary environments to rock physics (pp. 603-637). Berlin: Springer. https://doi.org/10.1007/978-3-642-34132-8_25 
Faleide, J. I., Myhre, A. M., \& Eldholm, O. (1988). Early tertiary volcanism at the western Barents Sea margin. In A. C. Morton, \& L. M. Parson (Eds.), Early tertiary volcanism and the opening of the NE Atlantic, Geological Society, London, Special Publications (Vol. 39, pp. 135-146). London: Geological Society.

Faleide, J. I., Pease, V., Curtis, M., Klitzke, P., Minakov, A., Scheck-Wenderoth, M., et al. (2018). Tectonic implications of the lithospheric structure across the Barents and Kara shelves. In V. Pease, \& B. Coackley (Eds.), Circum-Arctic lithosphere evolution, Geological Society, London, Special Publications (Vol. 460, pp. 285-314). London: Geological Society.

Faleide, J. I., Tsikalas, F., Breivik, A. J., Mjelde, R., Ritzmann, O., Engen, O., et al. (2008). Structure and evolution of the continental margin off Norway and Barents Sea. Episodes, 3, 82-91.

Fejerskov, M., Lindholm, C., Myrvang, A., \& Bungum, H. (2000). Crustal stress in and around Norway: A compilation of in situ stress observations. In A. Nøttvedt (Ed.), Dynamics of the Norwegian margin, Geological Society, London, Special Publications (Vol. 167, pp. 441-449). London: Geological Society.

Flesch, L. M., Holt, W. E., Haines, A. J., Wen, L., \& Shen-Tu, B. (2007). The dynamics of western North America: Stress magnitudes and the relative role of gravitational potential energy, plate interaction at the boundary, and basal tractions. Geophysical Journal International, 169(3), 866-896. https://doi.org/10.1111/j.1365-246X.2007.03274.x

Flesch, L. M., John Haynes, A., \& Holt, W. E. (2001). Dynamics of the India-Eurasia collision zone. Journal of Geophysical Research, 105(B8), 16,435-16,460. https://doi.org/10.1029/2001JB000208

Fletcher, R. (1991). Three-dimensional folding of an embedded viscous layer in pure shear. Journal of Structural Geology, 13, 97-96.

Gabrielsen, R. H., Færseth, R. B., Jensen, L. N., Kalheim, J. E., \& Riis, F. (1990). Structural elements of the Norwegian continental shelf, part I: The Barents Sea region. Norwegian Petroleum Directorate. Bulletin, 6, 1-47. Retrieved from http://npd.no/engelsk/infoserv/publ/ NPD_BulletinNo4.pdf

Gabrielsen, R. H., Grunnaleite, I., \& Rasmussen, E. (1997). Cretaceous and Tertiary inversion in the Bjørnyrenna fault complex, south-western Barents Sea. Marine and Petroleum Geology, 14(2), 165-178. https://doi.org/10.1016/S0264-8172(96)00064-5

Gac, S., Huismans, R. S., Simon, N. S. C., Faleide, J. I., \& Podladchikov, Y. Y. (2014). Effects of lithosphere buckling on subsidence and hydrocarbon maturation: A case-study from the ultra-deep East Barents Sea basin. Earth and Planetary Science Letters, 407, 123-133.

Gac, S., Huismans, R. S., Simon, N. S. C., Podladchikov, Y. Y., \& Faleide, J. I. (2013). Formation of intra-Cratonic basins by lithospheric shortening and phase changes: A case study from the ultra-deep East Barents Sea basin. Terra Nova, 25(6), 459-464. https://doi.org/ 10.1111/ter.12057

Gac, S., Klitzke, P., Minakov, A., Faleide, J. I., \& Scheck-Wenderoth, M. (2016). Lithosphere strength and elastic thickness of the Barents Sea and Kara Sea. Tectonophysics, 691, 120-132. https://doi.org/10.1016/j.tecto.2016.04.028

Gaina, C., Gernigon, L., \& Ball, P. (2009). Paleocene recent plate boundaries in the NE Atlantic and the formation of the Jan Mayen microcontinent. Journal of the Geological Society, 166(4), 601-616. https://doi.org/10.1144/0016-76492008-112

Gernigon, L., \& Brönner, M. (2012). Late Paleozoic architecture and evolution of the southwestern Barents Sea: Insights from a new generation of aeromagnetic data. Journal of the Geological Society, 169(4), 449-459. https://doi.org/10.1144/0016-76492011-131

Gernigon, L., Brönner, M., Roberts, D., Olesen, O., Nasuti, A., \& Yamasaki, T. (2014). Crustal and basin evolution of the southwestern Barents Sea: From Caledonian orogeny to continental breakup. Tectonics, 33, 347-373. https://doi.org/10.1002/2013TC003439

Gernigon, L., Brönner, M., Roberts, D., Olesen, O., Nasuti, A., \& Yamasaki, T. (2018). Crustal and basin evolution of the southwestern Barents Sea: From Caledonian orogeny to continental breakup. Tectonics, 33, 347-373. https://doi.org/10.1002/2013TC003439

Ghosh, A., Holt, W. E., \& Bahadori, A. (2019). Role of large-scale tectonic forces in intraplate earthquakes of central and eastern North America. Geochemistry, Geophysics, Geosystems, 20, 2134-2156. https://doi.org/10.1029/2018GC008060

Ghosh, A., Holt, W. E., \& Flesch, L. M. (2009). Contribution of gravitational potential energy to the global stress field. Geophysical Journal International, 179(2), 787-812. https://doi.org/10.1111/j.1365-246X.2009.04326.X

Ghosh, A., Holt, W. E., Wen, L., Haines, A. J., \& Flesch, L. M. (2008). Joint modelling of lithosphere and mantle dynamics elucidating lithosphere-mantle coupling. Geophysical Research Letters, 35, L16309. https://doi.org/10.1029/2008GL034365

Gion, A. M., Williams, S. E., \& Müller, R. D. (2016). A reconstruction of the Eurekan orogeny incorporating deformation constraints. Tectonics, 36, 304-320. https://doi.org/10.1002/2015TC004094

Grogan, P., Østvedt-Ghazi, A. M., Larssen, G. B., Fotland, B., Nyberg, K., Dahlgren, S., \& Eidvin, T. (1999). Structural elements and petroleum geology of the Norwegian sector of the northern Barents Sea. In A. J. Fleet, \& S. Boldy (Eds.), Petroleum geology of Northwest Europe: Proceedings of the 5th Conference, Geological Society, London, Special Publications (Vol. 86, pp. 247-259). London: Geological Society.

Hassaan, M., Faleide, J. I., Gabrielsen, R. H., \& Tsikalas, F. (2020). Carboniferous graben structures, evaporite accumulation in the southeastern Norwegian Barents Sea. Marine and Petroleum Geology, 112, 104038. https://doi.org/10.1016/j.marpetgeo.2019.104038

Heidbach, O., Ratjabi, M., Cui, X., Fuchs, K., Müller, B., Reinecker, J., et al. (2018). The world stress map database release 2016: Crustal stress pattern across scales. Tectonophysics, 744, 484-498. https://doi.org/10.1016/j.tecto.2018.07.007

Heidbach, O., Tingay, M., Barth, A., Reinecker, J., Kurfeß, D., \& Müller, B. (2010). Global crustal stress pattern based on the world stress map database release 2008. Tectonophysics, 482(1-4), 3-15. https://doi.org/10.1016/j.tecto.2009.07.023

Henriksen, E., Bjørnseth, H. M., Hals, T. K., Heide, T., Kiryukhina, T., Kløvjan, O. S., et al. (2011). Uplift and erosion of the greater Barents Sea: Impact on prospectivity and petroleum systems. In A. M. Spencer, A. F. Embry, D. L. Gautier, A. V. Stoupakova, K. Sørensen (Eds.), Arctic Petroleum Geology, Geological Society, London, Special Publications (Vol. 35, pp. 271-281). London: Geological Society.

Hughes, T. J. (2000). The finite element method. In Linear static and dynamic finite element analysis. Dover Publications, Inc.

Jackson, J. (2002). Strength of the continental lithosphere: Time to abandon the jelly sandwich? GSA Today, 9, 4-10.

Kairanov, B., Escalona, A., Mordasova, A., Sliwinska, K., \& Suslova, A. (2018). Lower Cretaceous tectonostratigraphic evolution of the north central Barents Sea. Journal of Geodynamics, 119, 183-198. https://doi.org/10.1016/j.jog.2018.02.009

Kerr, J. W. (1977). Cornwallis fold belt and the mechanisms of basement uplift. Canadian Journal of Earth Sciences, 14(6), 1374-1401. https://doi.org/10.1139/e77-123

Klitzke, P., Faleide, J. I., Scheck-Wenderoth, M., \& Sippel, J. (2015). A lithosphere-scale structural model of the Barents Sea and Kara Sea region. Solid Earth, 6(1), 153-172. https://doi.org/10.5194/se-6-153-2015

Klitzke, P., Franke, D., Ehrhardt, A., Lutz, R., Reinhardt, L., Heyde, I., \& Faleide, J. I. (2019). The Paleozoic evolution of the Olga Basin region, northern Barents Sea: A link to the Timanian orogeny. Geochemistry, Geophysics, Geosystems, 20, 614-629. https://doi.org/ 10.1029/2018GC007814

Kristensen, T. B., Rotevatn, A., Marvik, M., Henstra, G. A., Gawthorpe, R. L., \& Ravnås, R. (2018). Structural evolution of sheared margin basins: The role of strain partitioning. Sørvestnaget Basin, Norwegian Barents Sea. Basin Research, 30, 279-301. 
Kristoffersen, Y., \& Talwani, M. (1977). Extinct triple junction south of Greenland and the tertiary motion of Greenland relative to North America. Geological Society of America Bulletin, 88(7), 1037-1049. https://doi.org/10.1130/0016-7606(1977)882.0.co;2

Kwon, Y. W., \& Bang, H. (2000). The finite element method using MATLAB (2nd ed.). Boca Raton: CRC Press LLC.

Lechmann, S. M., May, D. A., Kaus, B. J. P., \& Schmalholz, S. M. (2011). Comparing thin-sheet models with 3-D multilayer models for continental collision. Geophysical Journal International, 187(1), 10-33. https://doi.org/10.1111/j.1365-246X.2011.05164.X

Medvedev, S. (2016). Understanding lithospheric stresses: Systematic analysis of controlling mechanisms with applications to the African plate. Geophysical Journal International, 207(1), 393-413. https://doi.org/10.1093/gji/ggw241

Molnar, P., \& Lyon-Caen, H. (1988). Some simple physical aspects of the support, structure, and evolution of mountain belts. GSA Special Reports, 218, 179-207.

Müller, R. D., Seton, M., Zahirovic, S., Williams, S. E., Matthews, K. J., Wright, N. M., et al. (2016). Ocean basin evolution and global-scale plate reorganization events since Pangea breakup. Annual Review of Earth and Planetary Sciences, 44(1), 107-138. https://doi.org/ 10.1146/annurev-earth-060115-012211

Nansen, F. (1904). The bathymetrical features of the north polar seas, with a discussion of the continental shelves and previous oscillations of the shore-line. In F. Nansen (Ed.), The Norwegian North Polar expedition 1893-1896, Scientific Results. Christiania: Jacob Dybwad.

Nielsen, S. B., Thomsen, E., Hansen, D. L., \& Clausen, O. R. (2005). Plate-wide stress relaxation explains European Paleocene basin inversions. Nature, 435(7039), 195-198. https://doi.org/10.1038/nature03599

Norwegian Petroleum Directorate (2017). Geological assessment of petroleum resources in eastern parts of Barents Sea north 2017. Retrieved from http://www.npd.no/en/Publications/Reports/Geological-assessment-of-petroleum-resources---Barents-Sea-north-2017/

Pascal, C., \& Gabrielsen, R. H. (2001). Numerical modeling of Cenozoic stress patterns in the mid-Norwegian margin and the northern North Sea. Tectonics, 20(4), 585-599. https://doi.org/10.1029/2001TC900007

Piepjohn, K., von Gosen, W., \& Tessensohn, F. (2016). The Eurekan deformation in the Arctic: An outline. Journal of the Geological Society, 173(6), 1007-1024. https://doi.org/10.1144/jgs2016-081

Riztmann, O., \& Faleide, J. I. (2009). The crust and mantle lithosphere in the Barents Sea/Kara Sea region. Tectonophysics, 470, 89-104. https://doi.org/10.1016/j.tecto.2008.06.018

Roberts, D., \& Siedlecka, A. (2002). Timanian orogenic deformation along the northeastern margin of Baltica, Northwest Russia and Northeast Norway, and Avalonian-Cadomian connections. Tectonophysics, 352(1-2), 169-184. https://doi.org/10.1016/S00401951(02)00195-6

Roest, W. R., \& Srivastava, S. P. (1989). Seafloor spreading in the Labrador Sea: A new reconstruction. Geology, 17(11), 1000-1004. https:// doi.org/10.1130/0091-7613(1989)017<1000:SFSITL>2.3.CO;2

Schiffer, C., \& Nielsen, S. B. (2016). Implications for anomalous mantle pressure and dynamic topography from lithospheric stress patterns in the North Atlantic realm. Journal of Geodynamics, 98, 53-69. https://doi.org/10.1016/j.jog.2016.03.014

Schiffer, C., Tegner, C., Schaeffer, A. J., Pease, V., \& Nielsen, S. B. (2018). High Arctic geopotential stress field and implications for geodynamic evolution. In V. Pease, \& B. Coackley (Eds.), Circum-Arctic lithosphere evolution, Geological Society, London, Special Publications (Vol. 460, pp. 441-465). London: Geological Society.

Schmalholz, S. M., Kaus, B. J. P., \& Burg, J. P. (2009). Stress-strength relationship in the lithosphere during continental collision. Geology, 37(9), 775-778. https://doi.org/10.1130/G25678A.1

Seton, M., Müller, R. D., Zahirovic, S., Gaina, C., Torsvik, T. H., Shephard, G. E., et al. (2012). Global continental and ocean basin reconstructions since 200 Ma. Earth-Science Reviews, 113, 212-270.

Shephard, G. E., Flament, N., Williams, S., Seton, M., Gurnis, M., \& Müller, R. D. (2014). Circum-Arctic mantle structure and long-wavelength topography since the Jurassic. Journal of Geophysical Research: Solid Earth, 119, 7889-7908. https://doi.org/10.1002/ 2014JB011078

Shulgin, A., Mjelde, R., Faleide, J. I., Høy, T., Flueh, E., \& Thybo, H. (2018). The crustal structure in the transition zone between the western and eastern Barents Sea. Geophysical Journal International, 214(1), 315-330. https://doi.org/10.1093/gji/ggy139

Skogseid, J., Pedersen, T., Eldholm, O., \& Larsen, B. T. (1992). Tectonism and magmatism during NE Atlantic continental break-up: The Vøring margin. In B. C. Storey, T. Alabaster, R. J. Plankhurst (Eds.), Magmatism and the Causes of Continental Break-Up, Special Publications (Vol. 68, pp. 305-320). London: Geological Society. https://doi.org/10.1144/GSL.SP.1992.068.01.19

Smelror, M., Petrov, O., Larssen, G. B., \& Werner, S. C. (2009). ATLAS: Geological history of the Barents Sea (p. 135). Trondheim: Geological Survey of Norway.

Sokoutis, D., Burg, J. P., Bonini, A., Corti, G., \& Cloetingh, S. A. P. L. (2005). Lithospheric-scale structures from the perspective of analogue continental collision. Tectonophysics, 406(1-2), 1-15. https://doi.org/10.1016/j.tecto.2005.05.025

Srivastava, S. (1978). Evolution of the Labrador Sea and its bearing on the early evolution of the North Atlantic. Geophysical Journal International, 52(2), 313-357. https://doi.org/10.1111/j.1365-246X.1978.tb04235.x

Stephenson, R., Schiffer, C., Peace, A., Nielsen, S. B., \& Jess, S. (2020). Late Cretaceous-Cenozoic basin inversion and paleostress fields in the North Atlantic-western Alpine-Tethys realm: implications for intraplate tectonics. Earth-Science Reviews. https://doi.org/10.1016/j. earscirev.2020.103252

Stephenson, R. A., \& Cloetingh, S. A. P. L. (1991). Some examples and mechanical aspects of continental lithospheric folding. Tectonophysics, 188(1-2), 27-37. https://doi.org/10.1016/0040-1951(91)90312-G

Tessensohn, F., \& Piepjohn, K. (2000). Eocene compressive deformation in Arctic Canada, North Greenland and Svalbard and its plate tectonic causes. Polarforschung, 68, 121-124.

Thatcher, W. (2009). How the continents deform: The evidence from tectonic geodesy. Annual Review of Earth and Planetary Sciences, 37(1), 237-262. https://doi.org/10.1146/annurev.earth.031208.100035

Turcotte, D. L., \& Schubert, G. (2002). Geodynamics (second ed.p. 456). Cambridge: Cambridge University Press. https://doi.org/10.1017/ CBO9780511807442

Ziegler, P. A., Cloethingh, S. A. P. L., \& Van Wees, J. D. (1995). Dynamics of intraplate compressional deformation - The Alpine foreland and other examples. Tectonophysics, 252(1-4), 7-59. https://doi.org/10.1016/0040-1951(95)00102-6

Ziegler, P. A., van Wees, J. D., \& Cloetingh, S. A. P. L. (1998). Mechanical controls on collision related compressional intraplate deformation. Tectonophysics, 31, 103-129. 